NBER WORKING PAPER SERIES

\title{
INSIDE THE WAR ON POVERTY: THE IMPACT OF FOOD STAMPS ON BIRTH OUTCOMES
}

\author{
Douglas Almond \\ Hilary W. Hoynes \\ Diane Whitmore Schanzenbach \\ Working Paper 14306 \\ http://www.nber.org/papers/w14306 \\ NATIONAL BUREAU OF ECONOMIC RESEARCH \\ 1050 Massachusetts Avenue \\ Cambridge, MA 02138 \\ September 2008
}

We would like to thank Justin McCrary for providing the Chay-Greenstone-McCrary geography crosswalk and Karen Norberg for advice on cause of death codes. This work was supported by a USDA Food Assistance Research Grant (awarded by Joint Center for Poverty Research at Northwestern University and University of Chicago), USDA FANRP Project 235 "Impact of Food Stamps and WIC on Health and Long Run Economic Outcomes", and the Russell Sage Foundation. We also thank Ken Chay, Janet Currie, Ted Joyce, Bob LaLonde, Doug Miller and seminar participants at the Harris School, Dartmouth, MIT, LSE, UC Irvine, IIES (Stockholm University), the NBER Summer Institute, and the SF Fed Summer Institute for helpful comments. Alan Barreca, Rachel Henry Currans-Sheehan, Elizabeth Munnich, Ankur Patel and Charles Stoecker provided excellent research assistance, and Usha Patel entered the regionally-aggregated vital statistics data for 1960-75. The views expressed herein are those of the author(s) and do not necessarily reflect the views of the National Bureau of Economic Research.

NBER working papers are circulated for discussion and comment purposes. They have not been peerreviewed or been subject to the review by the NBER Board of Directors that accompanies official NBER publications.

(C) 2008 by Douglas Almond, Hilary W. Hoynes, and Diane Whitmore Schanzenbach. All rights reserved. Short sections of text, not to exceed two paragraphs, may be quoted without explicit permission provided that full credit, including $(\mathcal{C}$ notice, is given to the source. 
Inside the War on Poverty: The Impact of Food Stamps on Birth Outcomes

Douglas Almond, Hilary W. Hoynes, and Diane Whitmore Schanzenbach

NBER Working Paper No. 14306

September 2008

JEL No. H51,I1,I3

\begin{abstract}
$\underline{\text { ABSTRACT }}$
This paper evaluates the health impact of a signature initiative of the War on Poverty: the roll out of the modern Food Stamp Program (FSP) during the 1960s and early 1970s. Using variation in the month the FSP began operating in each U.S. county, we find that pregnancies exposed to the FSP three months prior to birth yielded deliveries with increased birth weight, with the largest gains at the lowest birth weights. These impacts are evident with difference-in-difference models and event study analyses. Estimated impacts are robust to inclusion of county fixed effects, time fixed effects, measures of other federal transfer spending, state by year fixed effects, and county-specific linear time trends. We also find that the FSP rollout leads to small, but statistically insignificant, improvements in neonatal infant mortality. We conclude that the sizeable increase in income from Food Stamp benefits improved birth outcomes for both whites and African Americans, with larger impacts for births to African American mothers.,
\end{abstract}

Douglas Almond

Department of Economics

Columbia University

International Affairs Building, MC 3308

420 West 118th Street

New York, NY 10027

and NBER

da2152@columbia.edu

Hilary W. Hoynes

Department of Economics

University of California, Davis

One Shields Ave.

Davis, CA 95616-8578

and NBER

hwhoynes@ucdavis.edu
Diane Whitmore Schanzenbach

Harris School

University of Chicago

1155 E. 60th Street Suite 143

Chicago, IL 60637

schanzenbach@uchicago.edu 


\section{Introduction}

Compared to other high-income countries, newborn health in the U.S. is poor. Infant mortality is more than one-third higher than in Portugal, Greece, Ireland, and Britain, and double the rate in Japan and the Nordic countries. The rate of low birth weight is 25 percent higher in the U.S. than the OECD average (OECD Health Data, 2007). Explanations for these differences typically focus on differences in healthcare and health insurance. However, if the relationship between health and income is concave (Preston 1975), health at the bottom of the income distribution exerts a disproportionate effect on aggregate health measures (Deaton 2003). As a result, a less-studied hypothesis for poor newborn health is the relatively thick lower tail of the U.S. income distribution.

In this paper, we evaluate the health consequences of a sizable improvement in the resources available to America's poorest. We utilize the natural experiment afforded by the nationwide roll-out of the modern Food Stamp Program (FSP) during the 1960s and early 1970s. Hoynes and Schanzenbach's (2007) analysis of the PSID found that access to the FSP decreased outof-pocket food spending and increased total food spending, consistent with the predictions of canonical microeconomic theory. Furthermore, changes in food expenditures were similar to an equivalent-sized income transfer, implying that most recipient households were inframarginal. ${ }^{1} \mathrm{We}$ can therefore think of the FSP treatment as an exogenous increase in income for the poor.

Our identification strategy uses the sharp timing of the county-by-county rollout of the FSP, which was initially constrained by congressional funding authorizations. Specifically, we utilize information on the month the FSP began operating in each of the roughly 3,100 U.S. counties. After 1974, the FSP was available in all US counties. Moreover, the basic program parameters were set nationally by the Department of Agriculture. In the absence of state-level variation leveraged by economists to evaluate transfer programs, previous FSP research has typically resorted to strong assumptions as to the comparability of FSP participants and eligible non-participants (Currie 2003). Not surprisingly, the literature is far from settled as to what casual impact (if any) the FSP has on 
nutrition and health. As one of the largest anti-poverty programs in the U.S. - comparable in cost to the EITC and substantially larger than $\mathrm{TANF}^{2}$ - understanding FSP effects is valuable both in its own right and for what it reveals about the relationship between income and health.

We examine the impact of FSP rollout on birth weight, neonatal mortality, and fertility. Why focus on birth outcomes? First, birth outcomes improved substantially during the late 1960s and early 1970s. As shown in Figure 1a, after increasing from 1960 to 1965, the likelihood of low weight birth (below 2,500 grams) fell 12 percent for whites and 10 percent for nonwhites between 1965 and 1975. Neonatal mortality (death within the first month of life) fell by a third for whites and nonwhites between 1965 and 1975 (Figure 1b). This health improvement remains largely unexplained. ${ }^{3}$ Second, to the extent that nutritional changes improved birth outcomes, later-life health outcomes of these cohorts may have also benefitted (Barker 1992). ${ }^{4}$ Understanding the source of improvements in early-life health is therefore crucial. Third, the vital statistics data are ideally suited for analyzing FSP roll-out - the birth (death) micro data contain the county of birth (death) and the month of birth (death). This, combined with the large sample sizes (e.g., more than a million births per year) allows us to utilize the discrete nature of the FSP roll out with significant statistical power.

We find that newborn health improved promptly when the FSP was introduced. The FSP improved mean birth weight by about a half a percent for blacks and whites who participated in the program (effect of the treatment on the treated). Impacts were largest at the bottom of the birth weight distribution, reducing the incidence of low birth weight (less than 2,500 grams) among the treated by 7 percent for whites and between 5 and 11 percent for blacks. Changes in this part of the

\footnotetext{
1 FSP benefits were designed to cover a "thrifty food plan."

${ }^{2}$ The cost of the FSP was $\$ 33$ billion in 2006 (compared to $\$ 24$ billion for TANF, $\$ 33$ billion for the EITC, and $\$ 5.4$ billion for WIC).

${ }^{3}$ For Blacks, low birth weight and neonatal mortality improved substantially more in the North than in the South 1964-1975, while for Whites, gains were similar, and if anything slightly larger in the South. Improvements in Black post-neonatal mortality (death between months 1 and 12) have been attributed to the desegregation of southern hospitals (Almond, Chay, and Greenstone 2007).

${ }^{4}$ Improvements in cohort health for Blacks born in the late 1960s and early 1970s were found by Almond and Chay (2006).
} 
birth weight distribution are important as they are closely linked to other newborn health measures. An event study analysis confirms that the estimates are indeed capturing the effect of the FSP. We also find that the introduction of the FSP is associated with small improvements in neonatal infant mortality, but the results are not statistically significant. We find very small (but precisely estimated) impacts of the FSP on fertility, suggesting that the results are not biased by endogenous sample selection. All results are robust to various sets of controls, such as county fixed effects, state by year fixed effects, and even county specific linear trends. Moreover, FSP impact estimates are robust to county-by-year controls for federal spending on other social programs, suggesting our identification strategy is "clean".

Food Stamps are the fundamental safety net in the United States: unlike other means-tested programs, there is no additional targeting to specific sub-populations. Our analysis constitutes the first evidence that despite not targeting pregnant mothers (or even women), introduction of the FSP improved newborn health.

Our paper is organized as follows. Section 2 discusses the history of the FSP, Section 3 summarizes the existing literature, and Section 4 discusses how food stamps may affect infant health. The data is summarized in Section 5 and the methodology is presented in Section 6. The results are in Sections 7 and 8. We conclude in Section 9.

\section{Introduction of the Food Stamp Program}

The FSP is the most expansive of the U.S. food and nutrition programs. The program is means tested; eligibility requires satisfying income and asset tests. But unlike virtually all other means tested programs, there is no additional targeting to specific populations or family types (e.g. elderly or female heads of household). In this regard, the FSP is the fundamental safety net program in the United States. Benefits are an important component of the bundle of government transfers for low income families. For example, current benefits average about $\$ 200$ per recipient household per 
month.

The modern Food Stamp Program began with President Kennedy's 1961 announcement of a pilot food stamp program that was to be established in eight impoverished counties. The pilot programs were later expanded to 43 counties in 1962 and 1963. The success with these pilot programs led to the Food Stamp Act of 1964 (FSA), which gave local areas the authority to start up the Food Stamp Program (FSP) in their county. As with the current FSP, the program was federally funded and benefits were redeemable at approved retail food stores. In the period following the passage of the FSA, there was a steady stream of counties initiating food stamp programs and Federal spending on the FSP more than doubled between 1967 and 1969 (from \$115 million to \$250 million). Support for requiring food stamp programs grew due to a national spotlight on hunger (Berry 1984). This interest culminated in passage of 1973 Amendments to the Food Stamp Act, which mandated that all counties offer FSP by 1975.

Figure 2 plots the percent of counties with a FSP from 1960 to $1975 .{ }^{5}$ During the pilot phase (1961-1964), FSP coverage increased slowly. Beginning in1964, Program growth accelerated; coverage expanded at a steady pace until all counties were covered in 1974. Furthermore, there was substantial heterogeneity in timing of adoption of the FSP, both within and across states. The map in Figure 3 shades counties according to date of FSP adoption (darker shading denotes a later start up date). Our basic identification strategy considers the month of FSP adoption for each county the FSP "treatment."

Does the timing of FSP adoption appear exogenous? Prior to the FSP, some counties provided food aid through the commodity distribution program (CDP) — which took surplus food purchased by the Federal government as part of an agricultural price support policy and distributed those goods to the poor. The 1964 Food Stamp Act allowed for counties to voluntarily set up a FSP, but the Act also stated that no county could run both the FSP and the CDP. Thus, for counties which

\footnotetext{
${ }^{5}$ Counties are weighted by their 1970 population. Note this is not the food stamp caseload, but represents the percent of the U.S. population that lived in a county with a FSP.
} 
previously ran a CDP, adoption of the FSP implies termination of the CDP. (This transition in nutritional assistance would tend to bias downward FSP impact estimates, but as described below, we do not think this bias is substantial.) More importantly, the political accounts of the time suggest that debates about adopting the FSP pitted powerful agricultural interests against advocates for the poor (MacDonald 1977; Berry 1984). ${ }^{6}$ In particular, counties with strong support for farming interests (e.g., southern or rural counties) may have preferred to administer the CDP instead of the FSP, and may be late adopters of the FSP. On the other hand, counties with strong support for the low income population (e.g., northern, urban counties with large poor populations) may adopt FSP earlier in the period. This systematic variation in food stamp adoption could lead to spurious estimates of the program impact if those same county characteristics are associated with differential trends in the outcome variables.

In earlier work (Hoynes and Schanzenbach 2007), we documented that larger counties with a greater fraction of the population that was urban, black, or low income indeed implemented the FSP earlier (i.e. consistent with the historical accounts). Hoynes and Schanzenbach 2007 sought to predict FSP adoption date with 1960 county characteristics (i.e. characteristics recorded immediately prior to the pilot FSP phase). These "pre-treatment variables," complied from the 1960 Census of Population and 1960 Census of Agriculture, included the percent of the population that: 1) lives in an urban area; 2) is black; 3) is less than 5 years of age; 4) is 65 years or over; 5) has income less than $\$ 3,000$ (1959\$); as well as 7) the percent of land in the county that is farmland; and 8) county population. That analysis also showed that counties where more of the land is used in farming implement later. ${ }^{7}$

Nevertheless, these 1960 county characteristics explained very little of the variation in adoption dates. This is illustrated in Figure 4. Each panel is a scatter plot of a 1960 county characteristic (on the $\mathrm{x}$ axis) and county FSP implementation date (on the y axis) along with a

\footnotetext{
${ }^{6}$ In fact, as described in Berry (1984) and Ripley (1969), passage of the 1964 Food Stamp Act was achieved through classic legislative logrolling. The farm interest coalition (Southern Democrats, Republicans) wanted to pass an important cotton-wheat subsidy bill while advocates for the poor (Northern Democrats) wanted to pass the FSA. Neither had majorities, yet they made an arrangement, supported each others bills, and both bills passed.

${ }^{7}$ For more detail, see Appendix Table 1 in Hoynes and Schanzenbach (2007).
} 
univariate linear regression line. The county observations and regression are weighted by the county population. These figures show that the association between the county characteristics and the food stamp start date is weak and there is an enormous amount of variation that is not explained by the characteristics. This is consistent with the characterization of funding limits controlling the movement of counties off the waiting list to start up their FSP:

"The program was quite in demand, as congressmen wanted to reap the good will and publicity that accompanied the opening of a new project. At this time there was always a long waiting list of counties that wanted to join the program. Only funding controlled the growth of the program as it expanded" (Berry 1984, pp. 36-37).

We view the weakness of this model fit as a strength when it comes to our identification approach - in that much of the variation in the implementation of FSP appears to be idiosyncratic. Nonetheless, in order to control for possible differences in trends across counties that is spuriously correlated with the county treatment effect, all of our regressions include interactions of these 1960 pre-treatment county characteristics with time trends as in Acemoglu, Autor and Lyle (2004) and Hoynes and Schanzenbach (2007).

This period of FSP introduction took place as part of the much larger federal "war on poverty." Another source of bias may be the introduction or expansion during this period of programs such as Medicaid and AFDC. These programs, and virtually all means tested programs, are administered at the state level. Therefore (as we describe below), our controls for state by year fixed effects should absorb these program impacts. To be sure, however, our models include controls for per capita real county government transfers.

Near the end of our analysis period, the Special Supplemental Food Program for Women, Infants and Children (WIC) was introduced. WIC was designed to supplement Food Stamps, and benefits were made available to pregnant women and children up to age 5 in families with incomes up to the cutoff for free and reduced-price school lunches. The program was conceived in response to the perception that low-income mothers and children suffered from malnutrition that led to various 
ailments and high levels of post-neonatal mortality (Citizen's Board, 1968). ${ }^{8}$ WIC began as a pilot program in 1974, and was made permanent beginning late in 1975. Given the timing of WIC implementation relative to FSP, there is little concern that the introduction of WIC biases our estimates of the introduction of FSP. ${ }^{9}$

Finally, beyond establishing the exogeneity of FSP introduction, it is important to confirm that the FSP provided a treatment over and above the pre-existing CDP. Several pieces of evidence suggest this is true. The CDP was not available in all counties and recipients often had to travel long distances to pick up the items. Further, the commodities were distributed infrequently and inconsistently. Most importantly, the CDP provided a very narrow set of commodities - the most frequently available were flour, cornmeal, rice, dried milk, peanut butter and rolled wheat (Citizens' Board of Inquiry 1968). In contrast, Food Stamp benefits can be used to purchase all food items (except hot foods for immediate consumption, alcoholic beverages, and vitamins). Analyses of food intake in counties converting from CDP to FSP found that in its allowing participants to purchase a wide variety of food including fresh meat and vegetables, the FSP represented an important increase in the quality and quantity of food in comparison to the CDP (U.S. Congressional Budget Office 1977, Currie and Moretti 2008).

\section{Background Literature}

The goal of the food stamp program is to improve nutrition among the low income population. As such, there have been many studies that examine the impact of the FSP on nutritional intake and availability, food consumption, food expenditures and food insecurity (see Currie 2003 and Fraker 1990 for reviews of the literature).

Almost all existing studies of the impact of the FSP use research designs that rely on

\footnotetext{
${ }^{8}$ In the report Hunger, U.S.A., there were graphic descriptions of nutritional deficiencies among pregnant women, including "those in the lowest socioeconomic group [that] show a high incidence of clay or starch eating, from 40 to 50 percent in the Negroes and lower numbers in white women."

${ }^{9}$ Analyses limited to pre-1974 data are quite similar to results from the full time period, and are available upon request.
} 
comparisons of program participants to non-participants. This approach is subject to the usual criticisms regarding selection into the program. For example, a number of researchers (Currie 2003; Currie and Moretti 2008; Fraker 1990) have pointed out that if Food Stamp recipients are healthier, more motivated, or have better access to health care than other eligible women, comparisons between participants and non-participants could produce positive program estimates even if the true effect is zero. Conversely, if food stamp participants are more disadvantaged than other families, such comparisons may understate the program's impact. In fact, as reported in Currie (2003), several studies, including Basiotis et al. (1998) and Butler \& Raymond (1996), actually find that food stamp participation leads to a reduction in nutritional intake. These unexpected results are almost certainly driven by negative selection into the program.

Many researchers who evaluate the impact of other government programs avoid these selection problems by comparing outcomes across individuals living in states with different levels of benefit generosity or other program parameters. There is a long literature on the effects of cash assistance programs, for example, which is based on this type of identification strategy (Moffitt 1992; Blank 2002). Unfortunately, the FSP is a federal program for which there is very little geographic variation - aside from the variation we utilize in this paper - or variation in eligibility criteria or benefit levels, so prior researchers have had to employ alternative approaches.

Aside from the issue of research design, it is noteworthy that very few of the many FSP studies examine the impact on health outcomes. We are aware of two studies. Currie and Cole (1991) examine the impact of the FSP on birth weight using sibling comparisons and instrumental variable methods and find no significant impacts of the FSP. Our work is closest to Currie \& Moretti (2008), who use the county roll out of FSP in California to analyze birth outcomes. They find that FSP introduction was associated with a reduction in birth weight, which was driven particularly by teenagers having their first child and by changes for Los Angeles County. As discussed below, this negative effect is possible if the FSP led to fertility changes or increases in the survival of low birth 
weight fetuses.

More generally, there is a much larger literature on the determinants of infant health (see Currie (2008) for a comprehensive review). In general, the substantial improvement in infant health between 1965 and 1975 (Figures 1a and 1b) has not been a focus of this literature. This is a period of tremendous expansion in cash and noncash transfer programs. Health care expenditures accounted for the largest share of the War on Poverty and Great Society programs (Davis and Shoen, 1987). Assessment of whether these programs caused the health improvement is complicated by the proliferation of federal programs during the late 1960s, including expanded Maternal and Child Health spending, along with advent of the Medicaid and Medicare programs. To disentangle the FSP from these other programs, the county by month variation in FSP rollout is key.

Finally, in addition to new and expanded federal programs, Almond et al. (2007) argue that access to healthcare for blacks increased with the desegregation of Southern hospitals; generating a substantial reduction in black (but not white) post-neonatal mortality (deaths in months 2 to 12 ). This reduction in post-neonatal mortality was driven by reductions in deaths from conditions treatable in hospitals, such as pneumonia and gastroenteritis. Black neonatal mortality, by contrast, improved more in the North than in the South.

\section{Food Stamps and Infant Health}

In this section, we outline how food stamps may affect infant health. There is a large literature on the etiology of low birth weight, which we very briefly summarize. We then use this framework to discuss the possible ways that food stamps could affect infant health.

As suggested by Kramer (1987a, 1987b), birth weight is usefully decomposed in to: (1) that related to the gestation length (prematurity, or GL) and, (2) growth conditional on gestation length (intrauterine growth or IUG):

birth weight $=f(G L, I U G)$ 
Of the two, gestational length is thought to be more difficult to manipulate, though empirically more important than IUG in affecting birth weight in developed countries (Kramer 1987a, 1987b). In contrast, maternal nutrition and cigarette smoking are the two most important, potentially modifiable determinants of IUG (Kramer 1987a, 1987b). ${ }^{10}$ Finally, there is evidence that birth weight is generally most responsive to nutritional changes affecting the third trimester of pregnancy. ${ }^{11}$

How do food stamps enter this framework? As summarized above, the introduction of food stamps leads to increases in the quality and quantity of food. This suggests increases in birth weight (but not necessarily gestational length), with the largest impacts on treatment in the third trimester.

Our earlier work used the FSP roll out to examine the impacts of food stamps on food expenditures (Hoynes and Schanzenbach 2007). Canonical microeconomic theory predicts that inkind transfers have the same impact on spending as an equivalent cash transfer for consumers who are "infra-marginal" (that is, who would spend more on the subsidized good than the face value of the in-kind transfer). Using the PSID, they find that recipients of Food Stamps behave as if the benefits were paid in cash.

Based on the results of Hoynes and Schanzenbach (2007), we can think of the FSP introduction as an exogenous and sizable increase in income for the eligible population. The literature (see recent review in Currie 2008) provides few estimates of the causal impact of income on birth weight. Cramer (1995) finds that mothers with more income have higher birth weight babies, although income is identified cross-sectionally. Kehrer and Wolin (1979) find evidence that the Gary Income Maintenance Experiment improved birth weights, though the sample sizes are small and some of the estimates are imprecise. Currie and Cole (1993) document a negative cross-sectional relationship between AFDC (welfare) receipt and birth weight, but find that increased income from AFDC payments causes improvements in birth weight outcomes when unobservable characteristics

\footnotetext{
10 "Other public health interventions [besides reduced smoking] likely to improve intrauterine growth in developed countries include increases in caloric intake, especially in those settings where nutrition may be suboptimal for a substantial minority of the population" Kramer (1987) p. 509.

${ }^{11}$ See the literature review of Rush et al. (1980). For example, the cohort exposed to the Dutch Famine in the third trimester had lower average birth weight than cohorts exposed earlier in pregnancy (Painter et al., 2005).
} 
are taken into account through the use of instrumental variables or mother-specific fixed effects.

Baker (2008) uses the 1993 expansion in the EITC, which disproportionately benefitted families with two or more children, finding a 7 gram increase in the birth weight of subsequent children. In general the literature has been plagued by imprecise estimates due to small sample sizes as well as a lack of well-identified sources of variation in income. As a result, we argue that our paper provides some of the best evidence to date on the impact of income on birth outcomes.

Taking together the medical literature and the literature on the impacts of food stamps on nutrition, income, and expenditures, we expect that the introduction in the FSP should lead to improvements in infant health. According to the medical literature, $G L$ is a function of factors unlikely to be modified by FSP introduction. On the other hand, IUG is likely be directly impacted by the introduction of FSP. For example, low caloric intake during pregnancy is a major determinant of birth weight (Kramer 1987b). FSP benefits may work through other channels as well, for instance reducing stress experienced by the mother which itself has a direct impact on birth weight. Below we separately test for FSP impacts on length of gestation and birth weight. Further, following the evidence in the medical literature, our main estimates measure the FSP introduction as of the beginning of the third trimester.

There are other channels that could lead to negative impacts of FSP on infant health. First, if improvements in fetal health lead to fewer fetal deaths, there could be a negative compositional effect on birth weight from improved survivability of "marginal" fetuses. Second, even though recipients cannot purchase cigarettes directly with FSP benefits, nonetheless because resources to the household increase benefits may increase cigarette consumption, which would work to reduce birth weight. Finally, if FSP introduction leads to increases in fertility for disadvantaged women, this could also lead to negative effects on infant health.

Finally, it is important to analyze additional health measures in addition to birth weight: A final reminder concerns the need for future research to keep sight of the truly important outcomes of infant and child mortality, morbidity, and functional performance. After all, birth weight and gestational age are important only insofar as they affect these outcomes. 
Kramer (1987), p. 510

In addition to evaluating impacts on gestation length and the sex ratio, we also examine neonatal infant mortality. We chose neonatal mortality because it is commonly linked to the health environment during pregnancy; it is therefore plausible that improvements in prenatal nutrition may have been a factor. Post-neonatal mortality, by contrast, is viewed as being more determined by post-birth factors. ${ }^{12}$

We hypothesize that neonatal mortality would decline with improved prenatal nutrition, (although which stage of pregnancy is most important for neonatal mortality is less clear than for birth weight). Estimates from Almond, Chay, and Lee (2005) indicate that a 1 pound increase in birth weight causes neonatal mortality to fall by 7 deaths per 1,000 births, or $24 \% .^{13}$

\section{Data}

The data for our analysis are combined from several sources. The core data are two micro datasets on births and deaths from the National Center for Health Statistics. In some cases, we augment the core micro data with digitized print vital statistics documents to extend analysis to the years preceding the beginning of the micro data. These data are merged with county level data from several sources.

The first core data are the natality micro data from National Center for Health Statistics. The data are coded from birth certificates and are available beginning in 1968. Depending on the stateyear these data are either a 100 percent or 50 percent sample of births, and there are about 2 million observations per year. Reported birth outcomes include birth weight, gender, plurality, and (in some state-years) gestational length. Data on the month and county of birth permit linkage of natality

\footnotetext{
${ }^{12}$ The initial health at birth is generally much better among infants who die in the post-neonatal period than among infants dying in the first month of life. For example, while 72 percent of all neonatal deaths had a low birth weight (below 2,500 grams), only 20 percent of all post-neonatal deaths were low birth weight infants (Starfield 1985). Post-neonatal deaths tend to be caused by negative events after birth, most often by infectious diseases and accidents (Grossman \& Jacobowitz 1981). Further, post-neonatal deaths may be more responsive to hospital access than neonatal deaths.
} 
outcomes to the month the FSP was introduced in a given county. There are also (limited)

demographic variables including: age and race of the mother, and (in some state-years) education and marital status of the mother. Appendix Table 1 provides information on the availability of these variables over time.

We use the natality data and collapse the data to county-race-quarter cells covering the years 1968-1977. We use quarters (rather than months) to keep the sample size manageable. The results are unchanged if we instead use county-race-month cells. We stop in 1977 because this is two years after all counties have implemented the FSP. Further, program changes in the FSP enacted in 1978 led to increases in take-up. ${ }^{14} \mathrm{We}$ create the following birth outcomes using the natality data: mean birth weight and the fraction of births that are low birth weight $(<2,500$ grams), very low birth weight $(<1,500$ grams), and premature ( $<37$ weeks gestation).

It is unfortunate that the natality data begin in 1968 because - as shown in Figure 2-by 1968 half of the population lived in counties with a FSP in place. In the interest of examining the full FSP rollout, we obtained annual print vital statistics documents and digitized the available data. With these print documents, we hand entered counts of (1) the total number of births by county-year (not available by race) for 1959-1967, and (2) counts of births by birth weight ranges by state-race-year (not available by county) for $1959-1967 .^{15}$

Second, we utilize the micro data on deaths from the National Center on Health Statistics. The data are coded from death certificates and are available beginning in 1959. These data are the full universe of death certificates (except in 1972 when they are a 50 percent sample) and report the age and race of the decedent, the cause of death, and the month and county of death. We collapse the data to county-race-quarter cells covering the years 1959-1977.

Our mortality outcome is the neonatal mortality rate — defined as deaths in the first 28 days of

\footnotetext{
${ }^{13}$ Twin fixed effects estimate from Almond, Chay, and Lee (2005) for mortality, including congenital anomalies (Table III, $2^{\text {nd }}$ column).

${ }^{14}$ Specifically, in 1978 the purchase requirement was eliminated. Prior to this time, FSP participants were required to purchase their stamps at a cost that was a fraction of their face value.
} 
life per 1,000 live births. We focus on deaths from all causes; we use this because it gives us the most power (our observations are county-quarter-race so further cutting by detailed cause of death leads to very thin cell sizes) and it is not sensitive to changes in the cause of death codes (conversion from ICD-7 to ICD-8) in 1968. We have made an attempt to identify causes of death that could be affected by nutritional deficiencies and we also present results for these deaths and other deaths. ${ }^{16}$ Appendix Table 2 lists the causes of death and our mapping into those possibly affected by nutritional deficiencies.

Our main neonatal results use the natality micro data to form the denominator (live births in the same county-race-quarter); these data cover the years 1968-1977. In an extension we use the digitized vital statistics documents and county-year counts of births to construct the denominator for live births and therefore neonatal death rates (for all races) for $1959-1977 .^{17}$

We also use the natality data combined with population counts to construct fertility rates. The fertility rate is defined as births per 1,000 women ages $15-44$. Our main results use fertility rates by county-race-quarter for 1968-1977. The numerator is from the natality data (births collapsed to county-race-quarter). The denominator is from SEERS which we can use to create the population of women ages $15-44$ by county-race-year. ${ }^{18}$ We also use the digitized annual counts of births by county to construct fertility rates by county-year (not race, not quarter) for the full period 1959-1977.

We supplement the above with controls drawn from three sources. The key treatment or policy variable is the month and year that each county implemented a food stamp program. The data on county level food stamp start dates comes from USDA annual reports on county food stamp caseloads (USDA, various years). Our estimation sample drops Alaska because of difficulties in matching FSP service areas with counties.

Second, county characteristics are available in the 1960 City and County Data Book, which

\footnotetext{
${ }^{15}$ For historical vital statistics documents see http://www.cdc.gov/nchs/products/pubs/pubd/vsus/1963/1963.htm.

${ }^{16}$ We thank Karen Norberg for helping identify the cause of death classifications.

${ }^{17}$ We need quarterly births by race-county to match the quarterly deaths in the numerator. We use the distribution of births by quarter for each county in 1968 and assume that quarterly pattern holds for all years 1959-1967. In practice the "seasonality" of births across quarters is minimal.
} 
compiles data from the 1960 Census of Population and Census of Agriculture. These data are used to measure county pre-treatment variables for use as potential determinants of the timing of county FSP adoption. In particular, we construct the percent of the 1960 population that lives in an urban area, is black, is less than 5, is 65 or over, has income less than $\$ 3,000$ (1959\$), the percent of land in the county that is farmland, and log of the county population.

Third, we use data prepared by the Bureau of Economic Analysis, Regional Economic Information System (REIS). These data are used to construct annual, county real per capita measures of government transfers to individuals, including cash public assistance benefits (Aid to Families with Dependent Children AFDC, Supplemental Security Income SSI, and General Assistance), medical spending (Medicare and Military health care), and cash retirement and disability payments. ${ }^{19}$ Finally, we also use the REIS to construct annual real county per capita income. These data are available electronically beginning in 1968 . We extended the REIS data to 1959 by hand entering data from microfiche for 1959,1962 , and $1965-1968 .^{20}$

\section{Methodology}

We estimate the impact of the introduction of the FSP on county-level birth outcomes, infant mortality, and fertility, separately by race. Specifically, we estimate the following model:

$$
Y_{c t}=\alpha+\delta F S P_{c t}+\beta C B 60_{c} * t+\gamma X_{c t}+\eta_{c}+\delta_{t}+\mu_{s t}+\varepsilon_{c t}
$$

The observations are cell means at the county $c$ and quarter $t$ (race suppressed). $Y_{c t}$ is a measure of infant health or fertility defined in county $c$ at time $t$. In all specifications we include unrestricted fixed effects for county $\eta_{c}$ and time $\delta_{t}$. We examine the sensitivity to including state by year fixed effects $\mu_{\text {st }}$ or county specific linear time trends (not shown in equation).

\footnotetext{
${ }^{18}$ See National Cancer Institute http://seer.cancer.gov/popdata/download.html.

${ }^{19}$ Beginning in 1969, the REIS data permit more detailed categories for tabulating government transfers. However, because the natality data begin in 1968 and the mortality data begin in 1959, we have adopted these three categories. In analyses of the data limited to $1969+$, the results are robust to adding more detailed categories.

${ }^{20} \mathrm{We}$ used linear interpolation to fill in the missing years. The microfiche were obtained from Gary Kennedy of BEA.
} 
$F S P_{c t}$ is the food stamp treatment variable equal to one if the county has a food stamp program in place. The timing of the treatment dummy depends on the particular outcome variable used. For the analysis of births, we assign $F S P=1$ if there is a FSP in place at the beginning of the quarter prior to birth, to proxy for beginning of the third trimester. ${ }^{21}$ We assign the treatment at the beginning of the third trimester following the evidence that this period is the most important for determining birth weight. However, we explore the sensitivity to changing the timing of the FSP treatment. Neonatal deaths are thought to be tied primarily to pre-natal conditions and we therefore use the same FSP timing (we use the age at death and measure the FSP as of 3 months prior to birth, to proxy for the beginning of the third trimester). We have less guidance for the correct timing for FSP treatment for fertility — we explore FSP availability between 3 quarters prior to birth (to proxy for conception) and 7 quarters prior to birth.

The vector $X_{c t}$ contains the annual county-level controls from the REIS. In particular, it includes real, per-capita transfer spending on other government transfer programs (cash public assistance benefits, medical care, and retirement and disability payments) which are included to control for other expansions in Great Society programs that occurred during this time period. $X_{c t}$ also includes the log of real annual county per capita income to control for any coincident expansions in labor market opportunities or other factors at the county level.

$C B 60_{c}$ are the 1960 county characteristics, which we interact with a linear time trend to control for differential trends in health outcomes that might be correlated with the timing of FSP adoption.

We consider several outcome variables in our main specifications. First, using the natality data we infant health at birth: continuous mean birth weight in grams, the fraction low birth weight

\footnotetext{
${ }^{21}$ To be precise, because we collapse the data to the county-quarter the FSP variable can sometimes equal something other than a 0 or 1 . The natality data is available at the monthly level and we use that to assign FSP status as of 3 months prior to birth (proxy for beginning of the third trimester). When the data is collapsed to the county-quarter this policy variable is averaged among the 3-months of observations in that cell. Therefore the policy variable ranges from 0 to 1 , with most values at 0 or 1 .
} 
(less than 2500 grams, or about 5.5 pounds), and the fraction very low birth weight (less than 1500 grams, or about 3.3 pounds). Following the literature, we use low birth weight and very low birth weight to capture the apparent nonlinear effects in those ranges (see, e.g. Almond et al. 2005, Black et al. 2007). Further, we also examine the fraction of births that have a gestation below 37 weeks (considered pre-term) and the fraction of births that are female (to explore differential fetal survival). These measures are means within county-quarters. Second, using the mortality data we examine impacts on neonatal mortality rates (per 1000 live births) for all causes, and for those likely to be affected by nutritional deficiencies.

All estimates are weighted using the number of births in the county-race-quarter and the standard errors are clustered on county. Further, to protect against estimation problems associated with thinness in the data, for the natality (mortality) analysis we drop all county-race-quarter cells where there are fewer than 25 (50) births. ${ }^{22}$ The results are not sensitive to this sample selection.

\section{Results for Natality}

\subsection{Main Results}

Table 1A presents the main results for mean birth weight and the fraction of births that are low birth weight (LBW) for 1968-1977. Results are presented separately for whites (panel A) and blacks (panel B). For each outcome, we report estimates from four specifications with different controls. Column (1) includes county and time (year x quarter) fixed effects, county per capita income, REIS county-level per-capita transfers, and 1960 county characteristics interacted with linear time. The remaining columns control for trends in three ways: column (2) with state specific linear time trends, column (3) with unrestricted state by year fixed effects, and (4) with county specific linear time trends. In this and all subsequent tables, the number of observations refers to county-

\footnotetext{
${ }^{22}$ Neonatal mortality rates average 12 (19) per 1,000 births for whites (blacks) during our sample period. We use a higher threshold for the mortality analysis because of the low incidence of infant mortality.
} 
quarter cells. $^{23}$

The first four columns in Panel A report the impact of having FSP in place in the third trimester of pregnancy on mean birth weight for births to white women. These columns indicate a small statistically significant increase in birth weight for whites caused by exposure to FSP during the third trimester. The results are extremely robust across specifications, including controlling for county specific linear time trends. When the estimated coefficient is divided by mean birth weight, the resulting effect size is a 0.06 to 0.08 percent increase in birth weight (this is labeled in this and subsequent tables as "\% impact (coeff/mean)"). As shown in Panel B, the impact of FSP exposure on birth weight is 50-150 percent larger for blacks than whites. That, combined with a smaller average birth weight for blacks, implies an impact between 0.1 and 0.2 percent on blacks (about twice the impact on whites).

Only a subset of women who give birth are likely to be affected by FSP. While the coefficients reported above are valid estimates of the population impact of FSP, we may also want to know the impact among FSP recipients (i.e. the effect of the treatment on the treated). To calculate the implied impact on those who take up the FSP, we need an estimate of the participation rate of FSP benefits among women giving birth. Unfortunately we do not have information about food stamp participation in the natality data, nor do we have sufficient data to impute eligibility (e.g. income). Instead, we calculate FSP participation rates for groups "similar" to women giving birth. Specifically, we estimate the participation rate for all women with a child under 5 living in the house. (Participation rates look very similar if we alternatively use presence of a child below age 1 or 3.) The participation rates are calculated from the Current Population Survey (CPS), which first started asking about FSP participation in 1980 (after all counties had FSP in place). The estimated take-up rate for women with young children (under age 5) is 0.13 for whites and 0.41 for blacks. We can inflate the estimated effect by these participation rates for an estimate of treatment on the treated. The

\footnotetext{
${ }^{23}$ Note with 3142 counties and 40 quarters of data, the maximum number of observations would be about 125,000. For computation purposes, we drop cells with fewer than 25 births. This reduces the sample of blacks much more
} 
results indicate that the impact of FSP on participants' birth weight (labeled "Estimate, inflated") is between 15 and 20 grams for whites and 13 to 42 grams for blacks. The estimate expressed as a percent of mean birth weight (labeled "\% impact, inflated") is between 0.5 and 0.6 percent for whites and between 0.4 and 1.4 for blacks.

The results for birth weight (and the other outcomes described below) are very robust to adding more controls to the model. We view the specification with state by year unrestricted fixed effects as very encouraging — as we have controlled for a whole host of possibly contemporaneous changes to labor markets, government programs and other things that vary at the state-year level. Finally, we also find the results robust to adding county linear time trends (with some reduction for blacks). For the remainder of the tables, we adopt specification with state by year fixed effects as our base case specification. Results (not presented here) are the same if log of birth weight is used as the dependent variable instead.

Columns (5) through (8) repeat the exercise, this time with the fraction low birth weight (less than 2,500 grams) as the dependent variable. Exposure to FSP reduces low birth weight by a statistically significant 1 percent for whites (7-8 percent when inflated by participation rate), and a less precisely estimated 0.7 to 1.5 percent for blacks ( 5 to 12 percent when inflated by participation rate).

To further investigate the impact of the FSP on the distribution of birth weight, we estimated a series of models relating FSP introduction to the probability that birth weight is below a given gram threshold: 1500, 2000, 2500, 3000, 3250, 3500, 3750, 4000, 4500 (see Duflo 2001). We use the specification in column (3) with state by year fixed effects; the estimates and 90 percent confidence intervals are presented in Figure 5 (we plot “\% Impacts [coef/mean]” not inflated by program participation). Figure 5A displays the results and confidence intervals for whites. We find that the largest percent reduction in probability of birth weight below a certain threshold comes at very low represents $98 \%$ of white births and $94 \%$ of black births. 
thresholds of 1500 and 2000 grams. The impacts become gradually smaller as the birth weight threshold is increased to 2500 grams and above, until there is no difference for births below 3,750 grams. Results are larger for blacks (Figure 5B), showing a six percent decrease in the probability of a birth less than 1,500 grams, and an impact that declines at higher birth weights.

In order to gauge the magnitude of these effects, it is useful to compare the estimated effects to those implied by the previous literature. Cramer (1995) finds that a 1 percent change in the income-to-poverty ratio leads to a 1.05 gram increase in mean birth weight. The Hoynes and Schanzenbach (2007) estimates of the magnitude of food stamp benefits are $\$ 1900$ annually for participants (in 2005 dollars). Scaling those to match the units available in the literature (and treating FSP benefits as their face-value cash-equivalent) implies that food stamps increased the family income-to-poverty ratio of participants by 15 percent. The implied treatment-on-treated effect would therefore be approximately 16 grams, which is quite similar to the effects found in Table $1 \mathrm{~A} .^{24}$

Table 1B presents estimates for three additional outcome variables: the fraction of births that are less than 1,500 grams (already shown on Figure 5), that have gestation length less than 37 weeks (pre-term births), and the fraction of births that are female. These results show that FSP leads to a small but detectable decrease in pre-term births for whites; with statistically insignificant impacts for blacks. We find that the introduction of the FSP leads to a decrease in the fraction of births that are female. While small and statistically insignificant, this is consistent with recent work finding that prenatal nutritional deprivation tips the sex ratio in favor of girls (Mathews et al. 2008).

One limitation of these results is that micro-data on births by county is only available starting in 1968. By this point, almost half of the population was already covered by the FSP. To take advantage of the earlier program variation, we are able to push back models for low birth weight and very low birth weight to 1959 , but we can only measure outcomes at the state-race-year level (see discussion in data section). To construct state-level FSP treatment, we use the 1968 counts of number

\footnotetext{
${ }^{24}$ Assuming that birth weights are normally distributed, impacts of this implied magnitude would reduce the incidence of low birth weight by 5 percent, and reduce the incidence of very low birth weight by 7 percent.
} 
of births by county-month and calculate (for each state and year using the program variables) the percent of births in the state that were in counties with FSP in place 3 months prior to birth. Results are displayed in Appendix Table 3. Controls include state and year fixed effects, REIS variables, and state specific linear time trends; standard errors are clustered on state. We first present results for 1968+; where the data are identical to that used in Table 1 but are collapsed to the state level. The results show imprecise, but qualitatively similar, effects of FSP measured with this noisy treatment variable. (For example, the county analysis in Table 1A shows a -1 percent impact on LBW for whites and -1.5 percent for blacks compared to -0.4 percent for whites and -1.6 percent for blacks for the state-year data in Appendix Table 3). We then show the results for the full period (1959-1977) and the post-pilot program period (1964-1977). Whenever estimating models for the full FSP ramp up period, we look separately at the $1964+$ period because the pilot counties were clearly not exogeneously chosen. Using this earlier (but more aggregated) data, we get qualitatively similar but imprecise effects of the FSP. These results suggest that missing the pre-1968 period in our main results may not qualitatively affect our conclusions.

The existing literature suggests that nutrition has its greatest impact on birth weight during the third trimester. To explore the sensitivity of our results to the timing of the FSP introduction visà-vis the birth, Table 2 shows various reclassifications of the timing of exposure to FSP. We adopt the specification from column (3) of Table 1A for all columns, that is we control for 1960 county characteristics times linear time, per-capita transfer program spending, per-capita real income, unrestricted year and county fixed effects, and state by year fixed effects. The baseline specification — reprinted from Table $1 \mathrm{~A}$ - assigns the policy introduction as three months prior to birth, to proxy for beginning of the third trimester. Columns (2) and (3) move the policy treatment variable back to FSP's introduction two and three quarters before birth, respectively. Moving the treatment from third to second trimester reduces the impact of FSP substantially, though there is still a statistically significant impact on birth weight for blacks. Furthermore, assigning treatment at 
3 quarters before birth (proxy for conception) yields even smaller and statistically insignificant impacts. Similar results are found for fraction low and very-low birth weight. Finally, in columns (4) and (5) we include FSP during the third trimester as well as during either the second or first trimester. These results show that all of the action is through 3rd trimester exposure with insignificant impacts of the additional policy variable. We view these results as very compelling and important. First, they are consistent with the epidemiological evidence on the importance of 3rd trimester nutrition. Further, however, these results provide evidence that our model is not simply capturing a spurious correlation between FSP introduction and trends in infant outcomes at the county level. The reduction in the magnitude of the birth weight impact is consistent with results in Currie \& Moretti (2008). Their study of birth outcomes in California assigned the FSP treatment nine months prior to birth, and found comparatively limited impacts on birth weight.

Next we test for spurious trending in the county birth outcomes that might be loading on to FSP. Our first approach, shown in Table 3, is to include a one-year lead of the policy variable for each of the outcome variables presented in Tables 1A and 1B. There is no impact of the policy lead and the results for the main policy variable are qualitatively unchanged. Results from Tables 2 and 3 suggest we successfully isolated the effect of food stamps becoming available for pregnancies already "underway". This effect is found promptly after the FSP began operating in each county birth weights are higher just three months after a FSP started. Did county FSP operations truly "hit the ground running"? To evaluate the ramp up in FSP operations, we would like data on monthly FSP caseloads by county. Unfortunately, only annual caseload data are available. ${ }^{25}$ Nevertheless, we can use these data together with information on the month operations began to compare initial caseloads where operations began early in the reporting year (more lead time) to caseloads in counties where operations began late in the reporting year (little lead time). Appendix Figure 1 plots this comparison of caseloads - note the ramp up is only slightly faster in the counties with more lead

\footnotetext{
${ }^{25}$ Note we do not use the caseload data for identification because local take-up rates presumably register unobservables that may also impact birth outcomes (e.g. selective migration across counties).
} 
time. Further, note that over half of the "steady state" caseload is achieved in the first year, even for counties that begin operation late in the reporting year. This pattern suggests a rapid ramp-up was achieved.

\subsection{Event Study}

The pattern of estimates in Table 2 suggests that the FSP treatment effect is identified by the discrete jump in FSP at implementation and its impact on birth weight. In particular, we showed in Table 2 that as the timing of the treatment is shifted earlier in pregnancy, the estimated FSP effect on birth weight decreased substantially in magnitude. If instead identification were coming from some other trends in county outcomes that are correlated with FSP start month, then we would expect less sensitivity in the Table 2 results to the trimester to which the FSP treatment is assigned. However, there remains a concern that our results are driven by trends in county birth outcomes that are correlated with FSP implementation in a way that count linear trends do not capture.

This proposition can be evaluated more directly in an event study analysis. Specifically, we fit the following equation:

$$
Y_{c t}=\alpha+\sum_{i=-6}^{8} \pi_{i} 1\left(\tau_{c t}=i\right)+\eta_{c}+\delta_{t}+\gamma X_{c t}+\phi_{c} * t+\varepsilon_{c t}
$$

where $\tau_{c t}$ denotes the event quarter, defined so that $\tau=0$ for births that occur in the same quarter as the FSP began operation in that county, $\tau=1$ for births one quarter after the FSP began operation, and so on. For $\tau \leq-1$, pregnancies were untreated by a local program (births were before the program started). The coefficients are measured relative to the omitted coefficient $(\tau=-2) \cdot{ }^{26}$ Our event study model includes unrestricted fixed effects for county and time, county REIS variables, and county specific linear time trends.

In order to eliminate compositional effects on $\pi_{i}$, we restrict the sample to a balanced panel

\footnotetext{
${ }^{26}$ Because of the discrete nature of the event study model, the $\tau$ 's are formed by aggregating months to a quarter. For example, if the FSP started (or birth occurred) in January, February or March of 1970, then the FSP started (or birth occurred) in 1970 quarter 1 . Therefore when $\tau=0$ (birth quarter = policy commencement quarter) then the pregnancy could actually have been treated for between 0 and 3 months.
} 
of counties having births for all 15 event quarters: 6 quarters before implementation and 8 quarters after. As our natality data begins with January 1968, this means we exclude all counties with a FSP before July 1969.

Figure 6 plots the event-quarter coefficients from estimating equation (2) for Blacks. The figure also reports the number of county-quarter observations in the balanced sample and the difference-in-difference estimate on this sample. Panel A reports estimates when the dependent variable is birth weight and Panel B reports the estimates for fraction LBW. These figures show that there is a clear and sharp break in the trend for births, implying an increase. Similar patterns are observed when the dependent variable is the share of births below 1,500 grams (available upon request).

Figure 7 presents the analogous graphs for whites. Again, there is an increase in birth weights for births occurring very close to FSP implementation (panel A), although estimates are noisier than they were for blacks. For birth weight below 2,500 grams, there is a sustained decrease beginning at program implementation (panel B).

We view these results are compelling evidence that we are capturing a causal impact of FSP on infant health. Prior to implementation, there is little evidence of trending in the county outcomes. Further, there is a sharp improvement in birth around FSP implementation that is sustained. Importantly, births right around $\tau=0$ were conceived prior to FSP implementation, and therefore the likelihood that selection into childbearing accounts for the improvement in birth outcomes would seem remote. That such a prompt increase in birth weight observed with FSP inception indicates that potential confounders would have to mimic the timing of FSP roll out extremely closely.

\subsection{Extensions and Robustness Checks}

It is useful to explore whether the impacts of the FSP are larger among subsets of the sample that are more likely to be affected by the FSP. The natality data include education of the mother and presence of the father but because of missing data (some states do not include these on the birth 
certificates until later) we lose a substantial fraction of the sample (see Appendix Table 1).

Nonetheless, in results not shown, we estimate models by age of mother, education of mother, and presence of the father. Overall, the results show that the impacts are larger for older mothers (age 25 and over). None of the education results are statistically significant. This analysis did reveal that black mothers with no father present experience much larger impacts than all black women. This is consistent with the high participation rates among this group ( 0.70 compared to 0.50 for all blacks).

To get differences across groups, we then try different approach. In Table 4, we break counties into quartiles of FSP spending (per capita) as measured in 1978 (after the program is available). The results are quite striking (but imprecise)_FSP leads to an improvement in birth outcomes (increase in mean birth weight and a reduction in LBW) for those in the highest quartile FSP counties. The opposite pattern is evident in the lowest FSP counties. We found similar results when we stratified on quartiles of 1960 poverty rates (larger effects for high poverty counties).

There is some suggestion in the historical accounts that the impact might be different across geographic regions, or might differ by race across regions. In particular, participation in the program in the early years (after the county's initial adoption of FSP) was probably higher in urban counties and in the North. Barriers to accessing food stamps might have also differed between North and South, and may have interacted with race. ${ }^{27}$

Table 5 shows that the impact of FSP is larger and more statistically significant for both blacks and whites in urban counties. Interestingly, blacks appear to have larger effects outside the South, while whites appear to have larger effects in the South. These differences parallel the regional trends 1964-1975 - Blacks saw larger reductions in low birth weight (and neonatal mortality) in the North, while Whites saw larger declines in the South. The FSP impacts by South/Non-South, however, are less precisely estimated than the results by urban/nonurban. ${ }^{28}$

The main results are robust to many additional specification checks. One concern about the

\footnotetext{
${ }^{27}$ See, e.g., Citizens' Board (1968), chapter 4.

${ }^{28}$ We define the county as urban if more than 50 percent of the 1960 population in the county lives in an urban area.
} 
impacts of FSP on birth outcomes is that there are other programs that are being expanded at the same time, and so the effects we pick up are not the result of the FSP but may be driven by other changes. In results not shown (but available upon request), we find some evidence that FSP is not simply picking up the effect of other programs because the results are little changed whether we include or omit other county per capita transfer spending. Another way to check whether FSP is coincident with other health improvements, such as the expansion of access to hospitals in the South (Almond et al. 2007), is to test whether FSP impacts whether the birth was in a hospital and/or was attended by a physician. We observe this in the natality data, and Table 6 displays the results. The impact of the FSP on the fraction born in a hospital is small and not significant for whites, and small, insignificant and wrong-signed for blacks. Effects are also small and insignificant for percent born in a hospital or with a physician attending.

Finally, we investigate whether FSP is associated with higher fertility in Table 7. If children are a normal good, a program that increases household income might also increase the number of children. Further, this effect may lead to a negative composition bias as we would expect fertility to increase disproportionately among the disadvantaged (who have higher FSP participation and worse birth outcomes). The dependent variable is number of births in the race-county-quarter divided by the number of women aged 15-44, and the regressions are weighted by the population of women in each cell. The table presents several estimates, which vary depending on the timing of the FSP treatment: between 3 quarters prior to birth (proxy for conception) and 7 quarters prior to birth (1 year prior to conception). We find a small, positive, statistically insignificant effect of FSP on births. When this is scaled up by the participation rate, the treatment on the treated is about 1 percent for whites and 2 percent for blacks. In results not shown here, when we use data for the full FSP ramp up (back to 1959), the results are somewhat smaller. Overall, there is evidence only for very small and statistically insignificant impacts on fertility. Note, however, that we cannot distinguish how much of this fertility effect is behavioral versus the physiologic effect of greater fecundity from improved 
nutrition.

\section{Mortality Results}

Table 8 shows the main results for neonatal infant mortality rate for 1968 to 1977 . We present three outcomes: death rate for all causes, deaths possibly due to nutritional deficiencies, and other deaths (for definition see data section and Appendix Table 2). Because neonatal deaths are thought to primarily be related to impacts during the prenatal period, we time the FSP treatment as of a quarter prior to birth (to proxy for the beginning of the third trimester). In these models, we drop any race-county-quarter cell where there are fewer than 50 births. Results are weighted by number of births in the cell.

The neonatal mortality rate averages about 12 deaths per 1000 births for whites and 19 for blacks, with about half of the deaths where the cause of death indicates possibly affected by nutritional deficiencies. The results for whites and blacks show that the FSP leads to a reduction in infant mortality, with larger impacts for deaths possibly affected by nutritional deficiencies. Overall, the effect of the treatment on the treated (\% impacted, inflated) for all causes is about 4 percent for whites and between 4 and 8 percent for blacks. Few of the estimates, however, are statistically significant. These estimates are roughly in line with the birth weight-neonatal mortality rate relationship estimated by Almond, Chay, and Lee (2005): for whites, we estimate a very similar birth weight-mortality relationship, although the relationship between birth weight and mortality we estimate for Blacks is substantially stronger than in Almond, Chay, and Lee (2005). ${ }^{29}$ Finally, we view the results for "other deaths" (not affected by nutritional deficiencies), which are opposite signed and much smaller in magnitude, as solid evidence that they are capturing effects of the FSP.

Table 9 presents results for all races for the full $1959+$ period. We are unable to present results by race here because the denominator (live births by county-time) is not available by race

\footnotetext{
${ }^{29}$ While the mortality estimates for blacks are clearly noisy, a larger mortality effect is expected for Blacks as mean birth weight is 250 grams lower (Table 1), and the birth weight-mortality relationship is non-linear (stronger at low birth weights).
} 
prior to 1968. The first three columns replicate the results in Table 8 for 1968-1977 for all races. In the subsequent columns (for years 1959-1977 and 1964-1977) we find results very similar to those for 1968-1977. Overall, FSP implementation leads to a reduction in neonatal infant mortality, although not statistically significantly so.

\section{Conclusion}

The uniformity of the Food Stamp Program was designed to buffer the discretion States exercised in setting rules and benefit levels of other anti-poverty programs. This uniformity was deliberately preserved through the major reforms to welfare under the 1996 Personal Responsibility and Work Opportunity Reconciliation Act (Currie, 2003). An unintended consequence of this regularity has been to circumscribe the policy variation typically used by researchers to identify program impacts. As a result, surprisingly little is known about FSP effects.

In contrast to other major U.S. anti-poverty programs, Food Stamps was rolled out county by county. This feature of FSP implementation allows us to separate the introduction of Food Stamps from the other major policy changes of the late 1960s and early 1970s. Although FSP benefits were (and are) paid in vouchers that themselves could only be used to purchase food, because the voucher typically represented less than households spent on food (covering just the "thrifty food plan"), recipients were inframarginal and benefits were essentially a cash transfer (Hoynes \& Schanzenbach 2007).

We find this cash transfer improved birth outcomes, despite not being targeted at pregnant women (or even families with children). Consistent with epidemiological studies, FSP availability in the third trimester had the largest birth weight impact. Effects were larger in populations at greater nutritional risk -- relative to Whites, the increase in mean birth weight was 6 times larger among Black mothers where no father was present at delivery. The shift in birth weights was also larger at the bottom of the birth weight distribution, where birth weight is more closely linked to other health 
outcomes. Further, we find suggestive evidence of increased gestation length (reduced prematurity) resulting from FSP availability. We conclude the FSP yielded important -- and previously undocumented -- health benefits.

The strong statistical association between health and income unfolds during childhood, when low-income families are less able to protect children's health (Case, Lubotsky, and Paxson 2002). Our findings reveal that an exogenous increase in income during a well-defined period -- pregnancy - can improve infant health. Future work will evaluate whether this policy-induced health improvement persists into adulthood. 


\section{References}

Acemouglu, Daron, David Autor, and David Lyle (2004). "Women War and Wages: The Impact of Female Labor Supply on the Wage Structure at Mid-Century," Journal of Political Economy, 112(3): 497-551.

Almond, Douglas and Kenneth Y. Chay (2006). "The Long-Run and Intergenerational Impact of Poor Infant Health: Evidence from Cohorts Born During the Civil Rights Era," manuscript, UC Berkeley Department of Economics.

Almond, Douglas, Kenneth Y. Chay, and Michael Greenstone (2007). "Civil Rights, the War on Poverty, and Black-White Convergence in Infant Mortality in the Rural South and Mississippi," working paper No. 07-04, MIT Department of Economics.

Almond, Douglas, Kenneth Y. Chay, and David S. Lee (2005). "The Costs of Low Birth Weight," The Quarterly Journal of Economics, 120(3): 1031-1084.

Barker, D.J.P. (1992). Fetal and Infant Origins of Adult Disease (London: British Medical Journal 1992).

Baker, Kevin (2008). "Do Cash Transfer Programs Improve Infant Health: Evidence from the 1993 Expansion of the Earned Income Tax Credit," manuscript, University of Notre Dame.

Bastiotis, P., C. S. Cramer-LeBlanc, and E. T. Kennedy (1998). "Maintaining Nutritional Security and Diet Quality: The Role of the Food Stamp Program and WIC," Family Economics and Nutritional Review, 11, 4-16.

Berry, Jeffrey M., (1984). Feeding Hungry People: Rulemaking in the Food Stamp Program (New Brunswick, NJ: Rutgers University Press).

Black, Sandra E., Paul J. Devereux, and Kjell G. Salvanes (2007). "From the Cradle to the Labor Market? The Effect of Birth Weight on Adult Outcomes," Quarterly Journal of Economics, 122(1): 409-439.

Blank, Rebecca (2003). "Evaluating Welfare Reform in the United States," The Journal of Economic Literature, 40(4): 1105-1166.

Butler, J.S. and J.E. Raymond (1996). "The Effect of the Food Stamp Program on Nutrient Intake," Economic Inquiry, 34(4): 781-98.

Citizens' Board of Inquiry into Hunger and Malnutrition in the United States (1968). Hunger, U.S.A. Boston: Beacon Press.

Cleaveland, Frederick N. (1969). Congress and Urban Problems: A Casebook on the Legislative Process (Washington, DC: The Brookings Institution) 279-310.

Corman, Hope and Michael Grossman (1985). “Determinants of Neonatal Morality Rates in the U.S. A Reduced Form Model,” Journal of Health Economics, 4(3): 213-236.

Cramer, James (1995). "Racial and Ethnic Differences in Birth Weight: The Role of Income and Financial Assistance," Demography 32(2): 231-247.

Currie, Janet (2003). "Food and Nutrition Programs" in Means-tested Transfer Programs in the U.S., Robert Moffitt, ed (Cambridge, MA: NBER). 
Currie, Janet (2006). Poverty, the Distribution of Income, and Public Policy (New York: Russell Sage Foundation).

Currie, Janet (2008). "Healthy, Wealthy and Wise: Socioeconomic Status, Poor Health in Childhood, and Human Capital Development.” NBER Working paper 13987.

Currie, Janet and Nancy Cole (1991). "Does Participation in Transfer Programs During Pregnancy Improve Birth Weight?” NBER Working paper 3832.

Currie, Janet and Nancy Cole (1993). "Welfare and Child Health: The Link Between AFDC Participation and Birth Weight." American Economic Review 83(4): 971-985.

Currie, Janet and Enrico Moretti (2008). "Did the Introduction of Food Stamps Affect Birth Outcomes in California?" in Making Americans Healthier: Social and Economic Policy as Health Policy, R. Schoeni, J. House, G. Kaplan, and H. Pollack, editors, Russell Sage Press.

Davis, Karen and Cathy Schoen (1978). Health and the War on Poverty: A Ten-Year Appraisal (The Brookings Institution).

Deaton, Angus (2003). "Health, Inequality, and Economic Development.” Journal of Economic Literature, XLI March, 113-158.

Duflo, Esther (2001). "Schooling and Labor Market Consequences of School Construction in Indonesia: Evidence from an Unusual Policy Experiment." American Economic Review 91(4):795813.

Fraker, Thomas (1990). "Effects of Food Stamps on Food Consumption: A Review of the Literature," report of Mathematica Policy Research. Washington, DC.

Grossman, Michael and Steven Jacobowitz (1981). "Variations in Infant Mortality Rates among Counties of the United States: The Roles of Public Policies and Programs," Demography, 18(4): $695-713$.

Hoynes, Hilary W. and Diane Whitmore Schanzenbach (2007). "Consumption Responses to In-Kind Transfers: Evidence from the Introduction of the Food Stamp Program,” NBER Working Paper No. 13025.

Kehrer, Barbara H. and Charles M. Wolin (1979) "Impact of Income Maintenance on Low Birth Weight: Evidence from the Gary Experiment," Journal of Human Resources 14(1):434-462.

Kramer, Michael S. (1987a) "Intrauterine Growth and Gestational Determinants," Pediatrics, 80:502-511.

Kramer, Michael S. (1987b) "Determinants of Low Birth Weight: Methodological Assessment and Meta-Analysis," Bulletin of the World Health Organization 65(5):633-737.

MacDonald, Maurice (1977). Food, Stamps, and Income Maintenance (Madison, WI: Institute for Poverty Research).

Mathews, Fiona, Paul J. Johnson and Andrew Neil (2008). "You are what your mother eats: evidence for maternal preconception diet influencing foetal sex in humans," Proceedings of the Royal Society, 275(1643):1661-8.

Mays, Benjamin E. and Leslie W. Dunbar (1968). Hunger, USA (Washington, DC: The New Community Press), the Citizens' Board of Inquiry into Hunger and Malnutrition in the United States. 
Moffitt, Robert (1992). "Incentive Effects of the US Welfare System," Journal of Economic Literature, 30(1): 1-61.

National Center for Health Statistics (various years). Health, United States, Hyattsville MD. Downloaded from: http://www.cdc.gov/nchs/products/pubs/pubd/hus/previous.htm\#editions.

National Center for Health Statistics (1984). "Vital Statistics of the United States, 1984, Volume 2 Mortality, Part A.”

National Center for Health Statistics (2002). "National Vital Statistics Reports," Volume 50, Number 15.

OECD Health Data (2007). OECD Health Data 2007: Statistics and Indicators for 30 Countries.

Oliveira, Victor, Elizabeth Racine, Jennifer Olmsted, and Linda M. Ghelfi (2002). "The WIC

Program: Background, Trends and Issues," report no. FANRR27: Food Assistance and Nutrition

Research, Economic Research Service, USDA.

Painter, Rebecca C., Tessa J. Rosebooma, and Otto P. Bleker (2005). "Prenatal exposure to the Dutch famine and disease in later life: An overview," Reproductive Toxicology, 20(3): 345-352.

Preston, Samuel H (1975). "The Changing Relation Between Mortality and Level of Economic Development," Population Studies 29: 231-248.

Ripley, Randall B. (1969). "Legislative Bargaining and the Food Stamp Act, 1964” in Congress and Urban Problems: A Casebook on the Legislative Process, Frederick N. Cleaveland, editor, The Brooking Institution.

Rush, David, Zena Stein, and Mervyn Susser (1980). Diet in Pregnancy: A Randomized Controlled Trial of Nutritional Supplements (New York: Alan R. Liss, Inc. 1980).

Schanzenbach, Diane Whitmore (2008) "What are Food Stamps Worth?” mimeo.

Starfield, Barbara (1985). "Postneonatal Mortality," Annual Review of Public Health, 6: 21-40.

U.S. Congressional Budget Office (1977). "The Food Stamp Program: Income or Food Supplementation?” Washington, U.S. Government Printing Office.

U.S. Department of Agriculture (various years). "Food Stamp Program, Year-End Participation and Bonus Coupons Issues," Technical report, Food and Nutrition Service.

U.S. Department of Health, Education and Welfare (various years). "Vital Statistics of the United States, Volume I.” (1959-1967). 
Figure 1a: Percent of Births Less than 2,500 grams, by Race

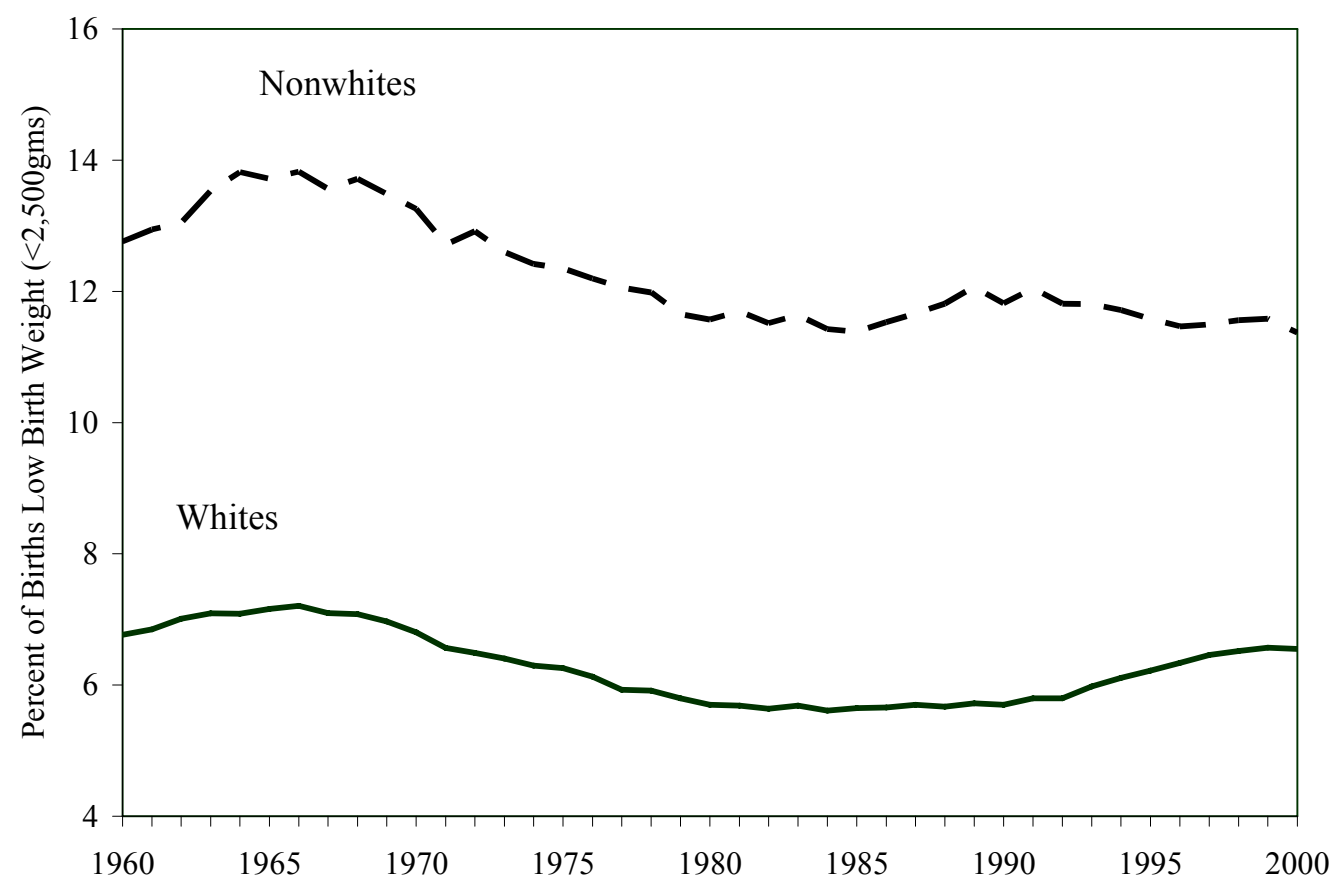

Figure 1b: Neonatal Infant Mortality Rate, by Race

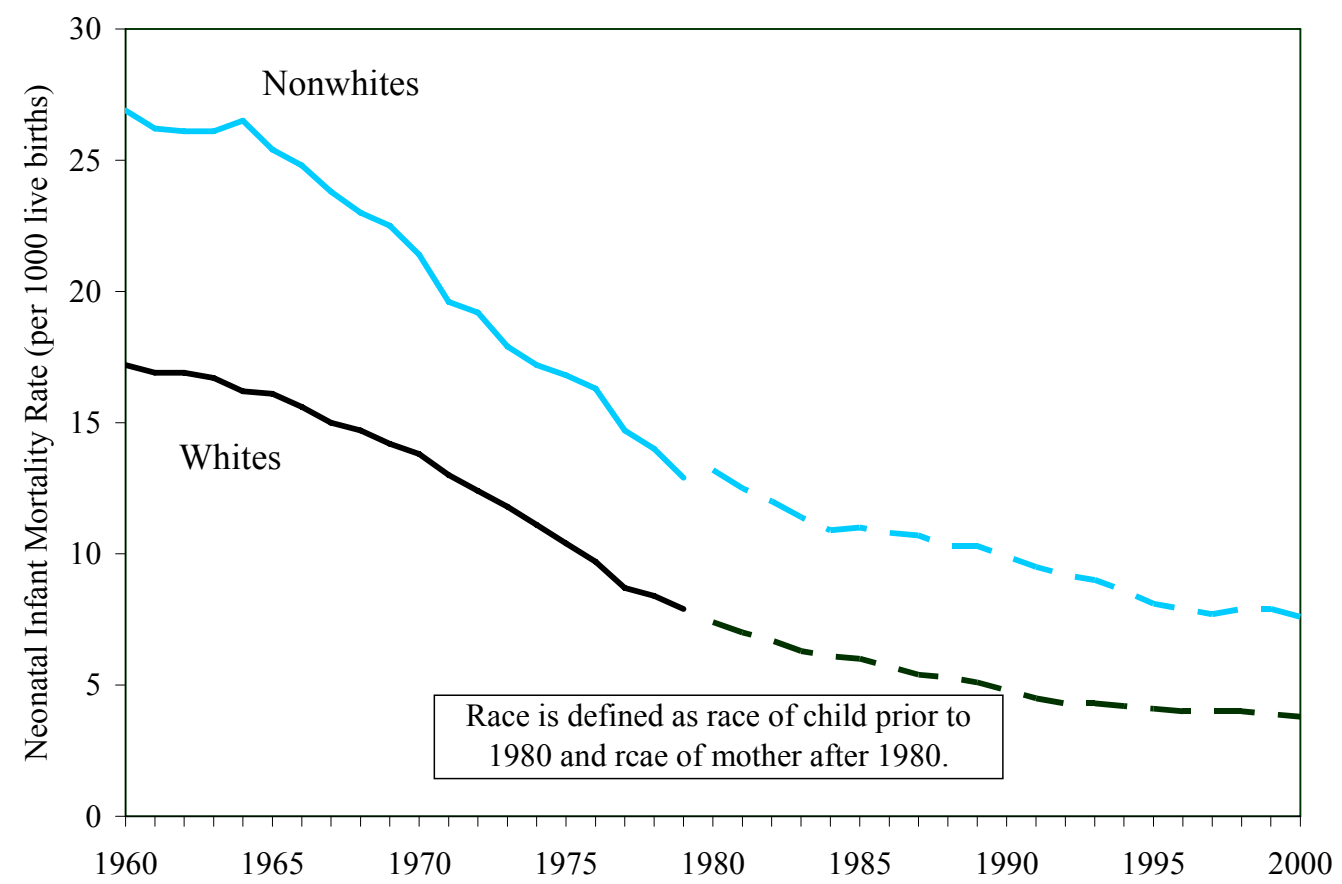

Source: Tabulations of low birth weight for 1959-1967 are authors' tabulations of digitized vital statistics documents on state-year-race counts of births by birth weight category from U.S. Department of Health, Education and Welfare (various years); data for 1968-1977 are authors' tabulations of natality micro data; and for 1978-2000 see National Center for Health Statistics (various years). Tabulations of neonatal infant mortality (deaths in first 28 days per 1000 live births) for 1960-1974 see Table 2-1 in National Center for Health Statistics (1987); and for 1975-2000 see Table 34 of National Center for Health Statistics (2002). 
Figure 2: Weighted Percent of Counties with Food Stamp Program, 1960-1975

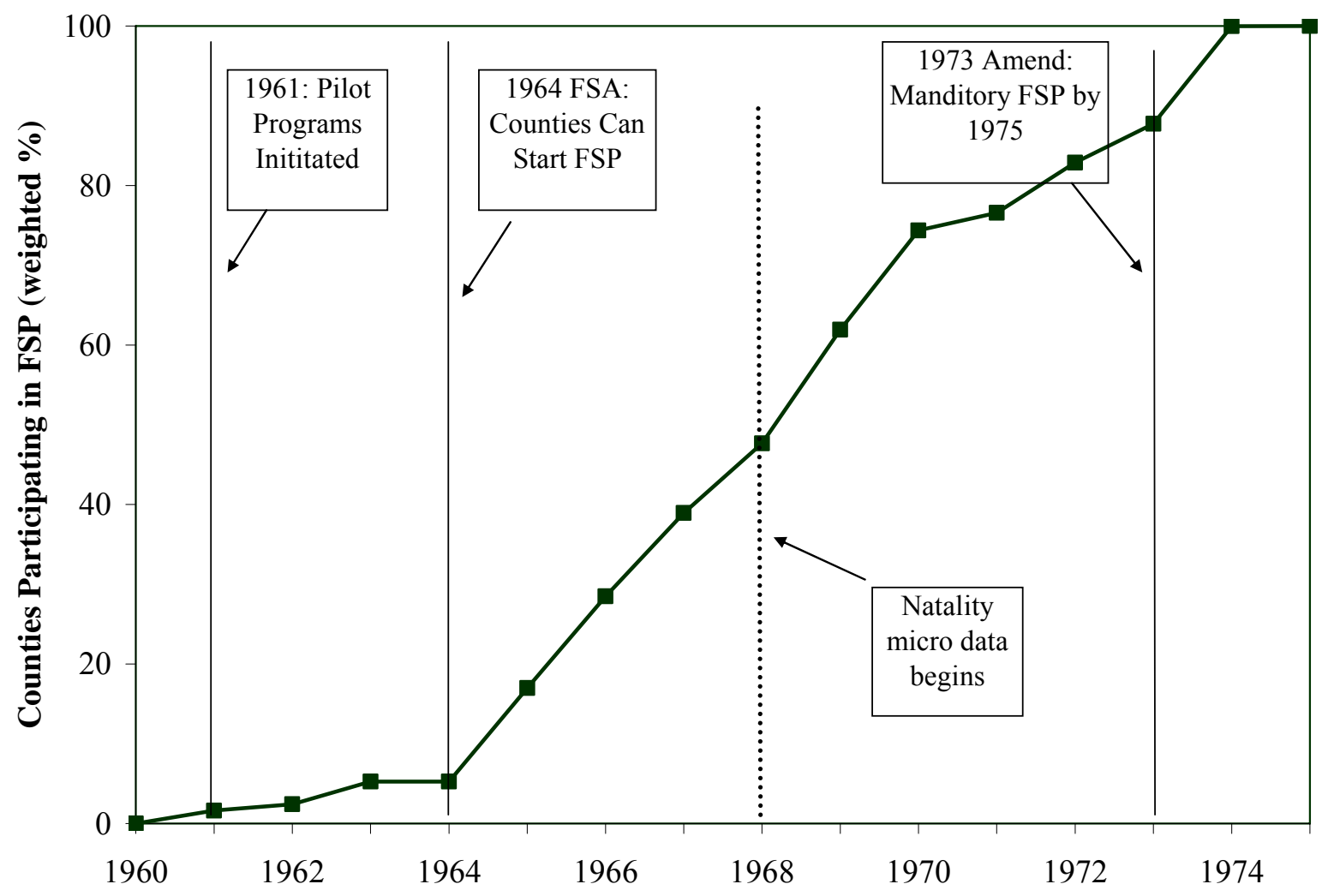

Source: Authors' tabulations of food stamp administrative data (U.S. Department of Agriculture, various years). Counties are weighted by their 1960 population. 
Figure 3: Food Stamp Program Start Date, By County (1961-1975)

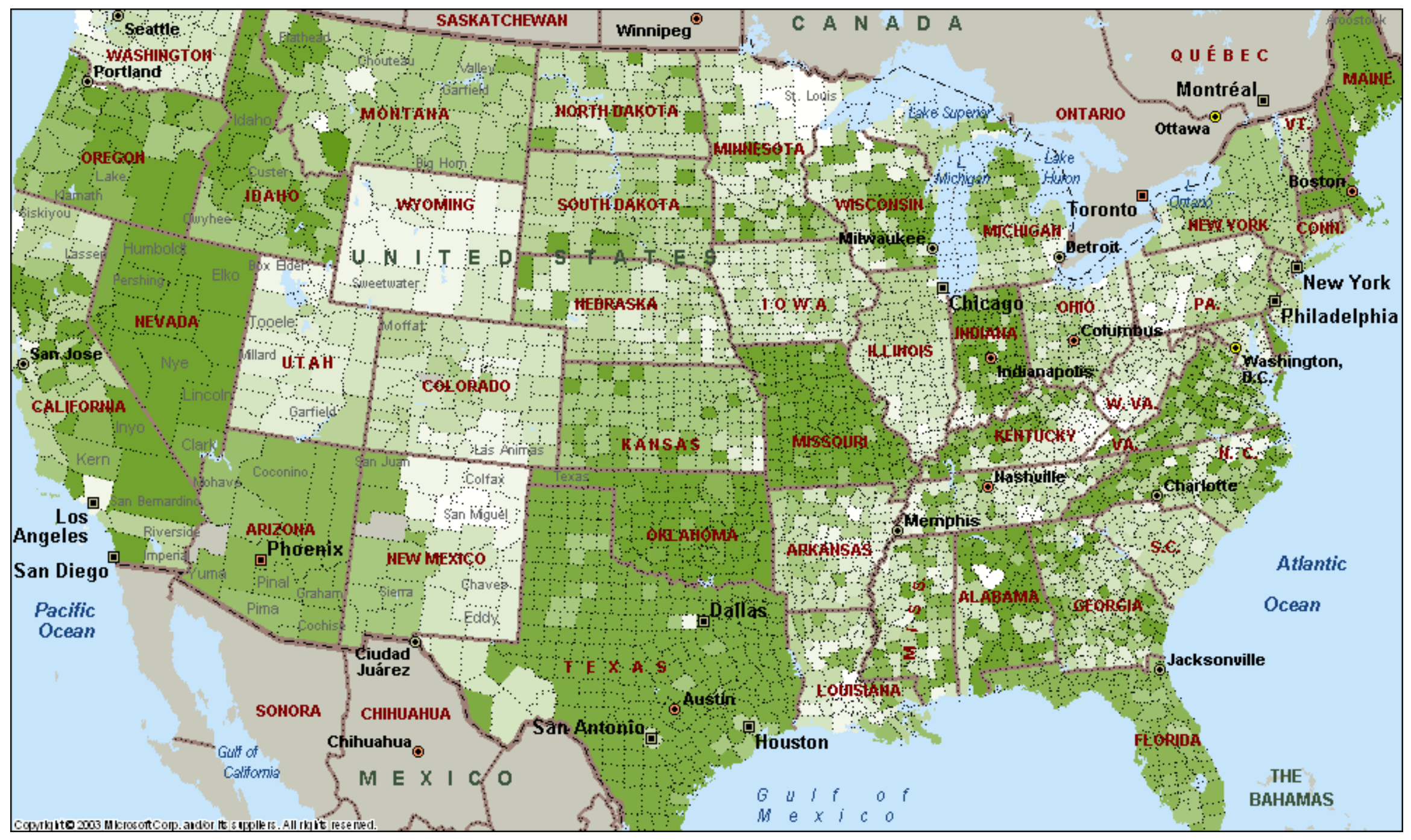

Note: Authors' tabulations of food stamp administrative data (U.S. Department of Agriculture, various years). The shading corresponds to the county FSP start date, where darker shading indicated later county implementation. 
Figure 4: 1960 County Characteristics and County Food Stamp Start Date

(a) Percent Black

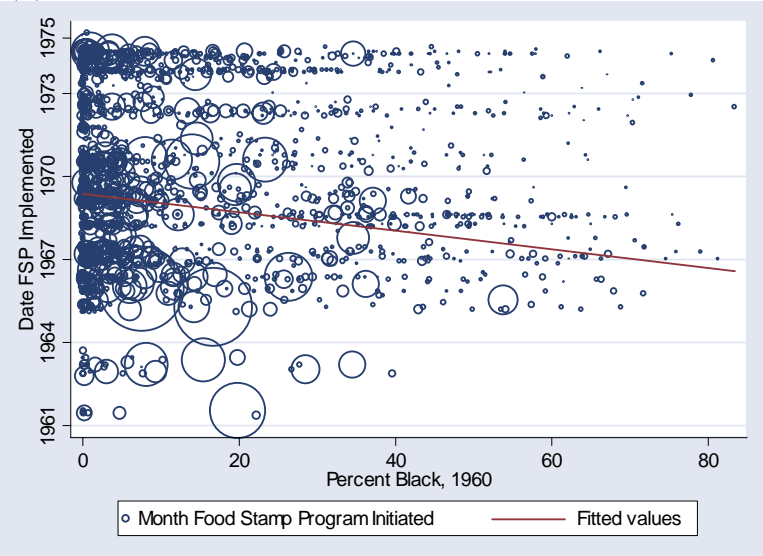

(b) Log of Population

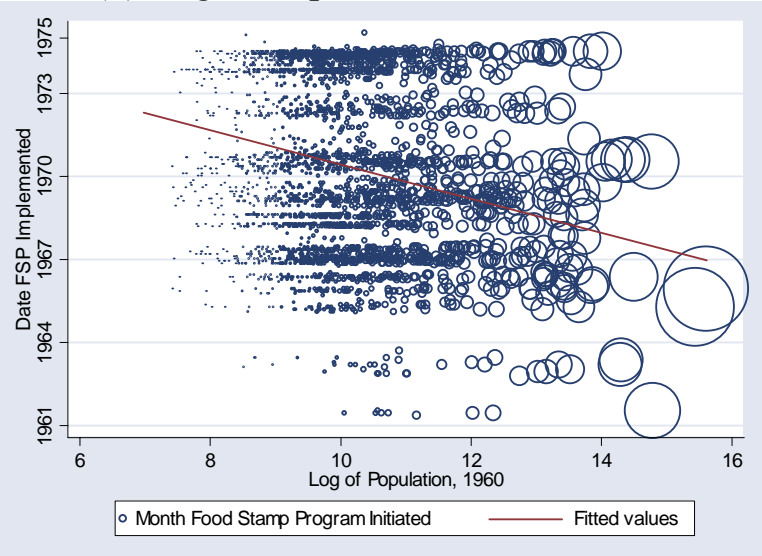

(c) Percent with Income $<\$ 3,000$

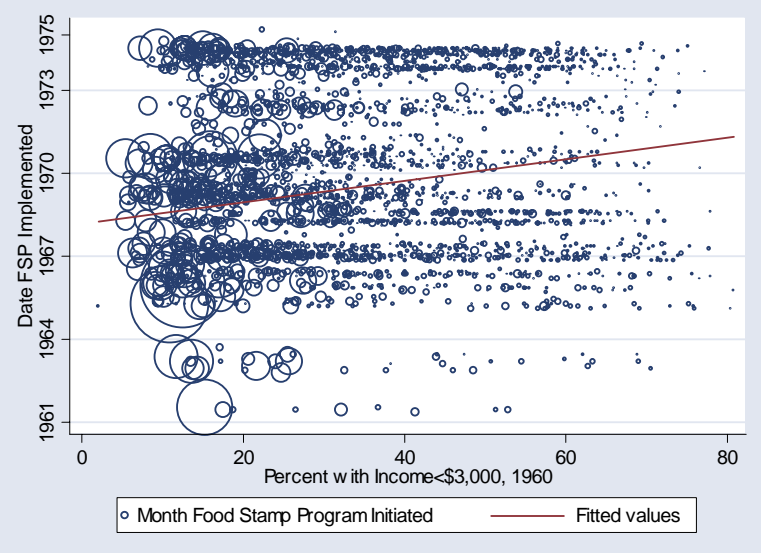

(d) Percent Urban

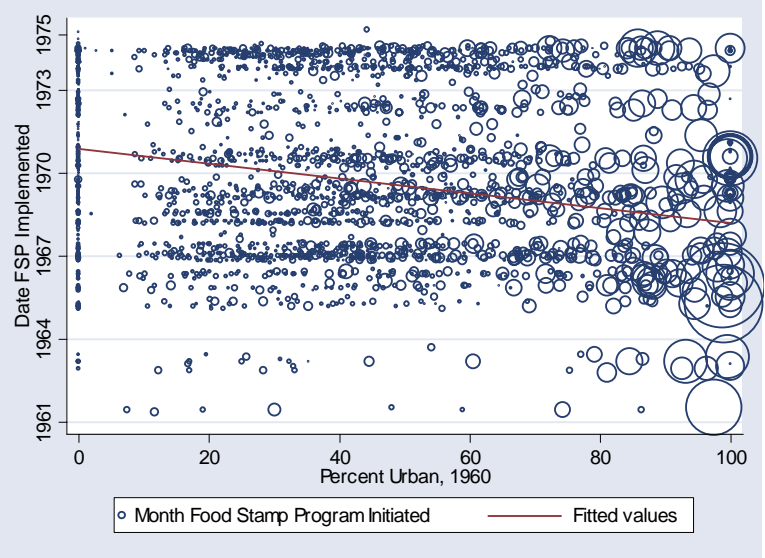

(e) Percent of Land in Farming

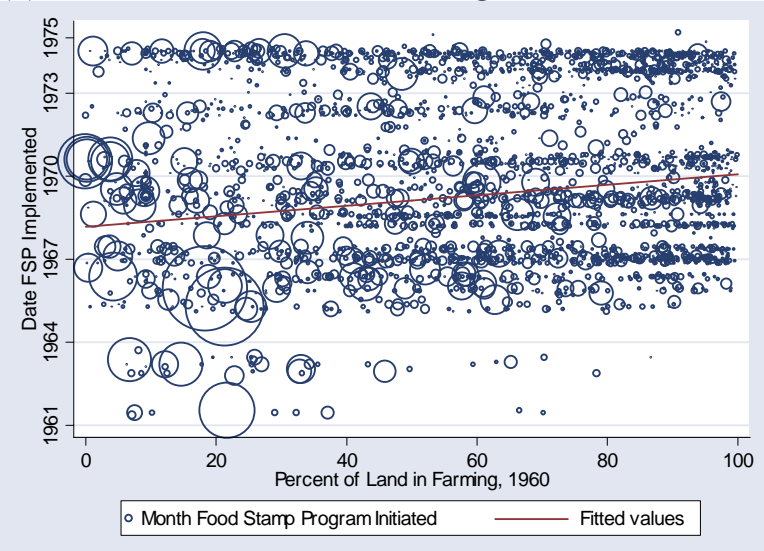

(f) Percent Age $>65$

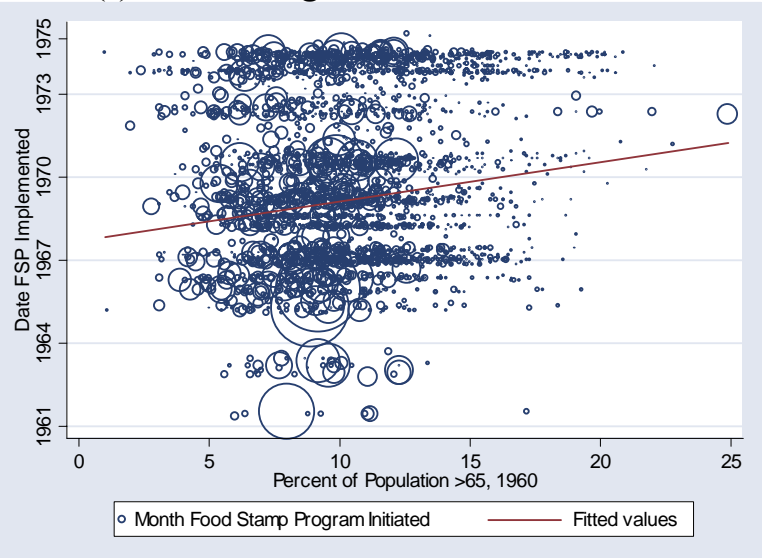

Note: Each graph provides a scatter plot of a 1960 county characteristic (x-axis) against the food stamp start date (y-axis) where the points are weighted by the 1960 county population. The graphs also contain the linear fit where the regression is weighted by 1960 county population. 1960 County characteristics are from the 1960 Census of Population and Agriculture. The FSP implementation dates are from U.S. Department of Agriculture (various years). 
Figure 5: Effects of FSP Implementation on Distribution of Birth Weight, Percent Impacts (Coef/Mean)

(a) Whites

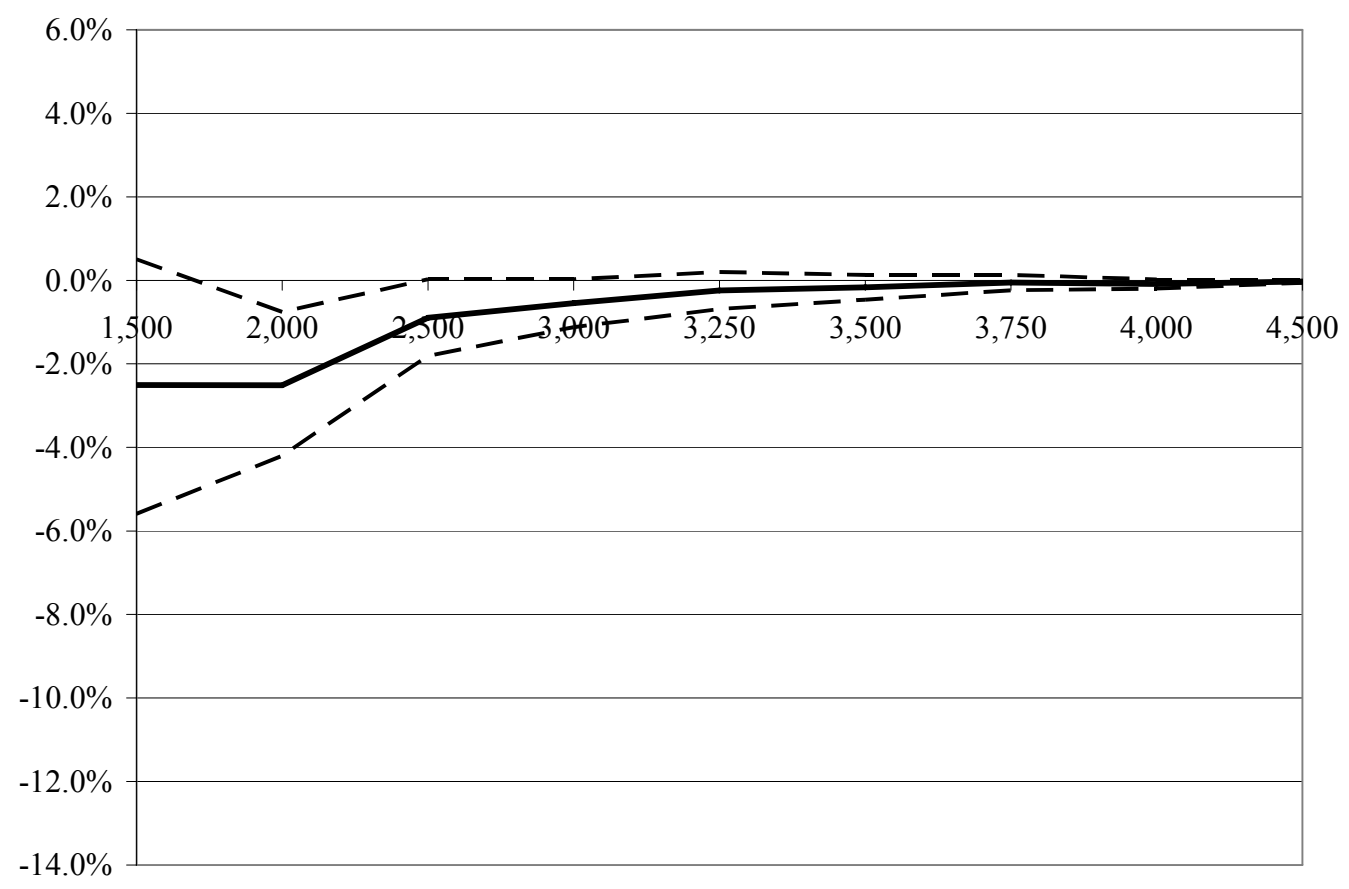

(b) Blacks

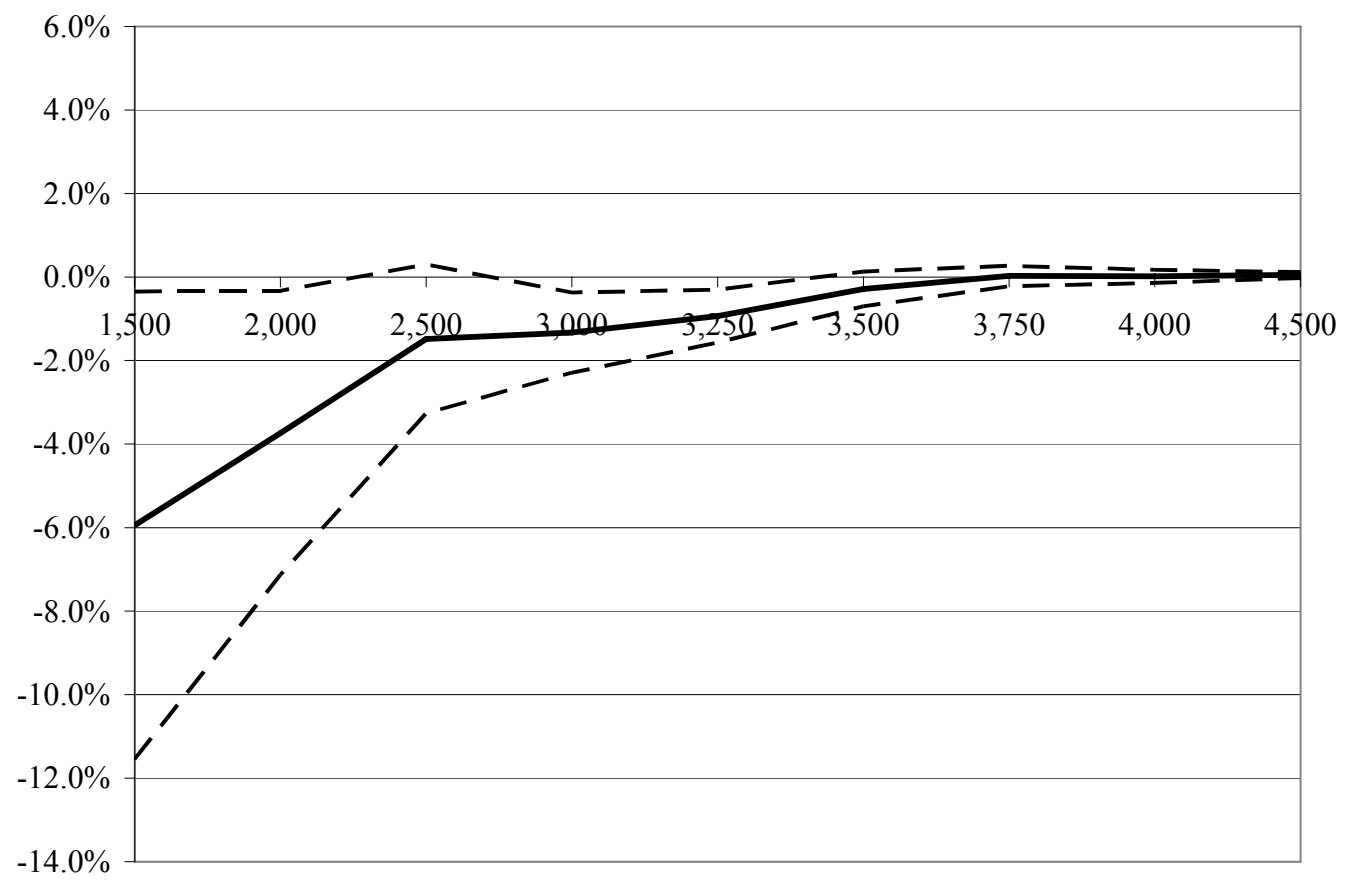

Notes: The graph shows estimates and 90 percent confidence intervals for the estimate of the impact of FSP implementation on the fraction of births in the county-quarter cell that is below each specified number of grams. The specification is given by column (3) in Table 1A. 
Figure 6: Event Study Analysis for Blacks

(a) Birth weight

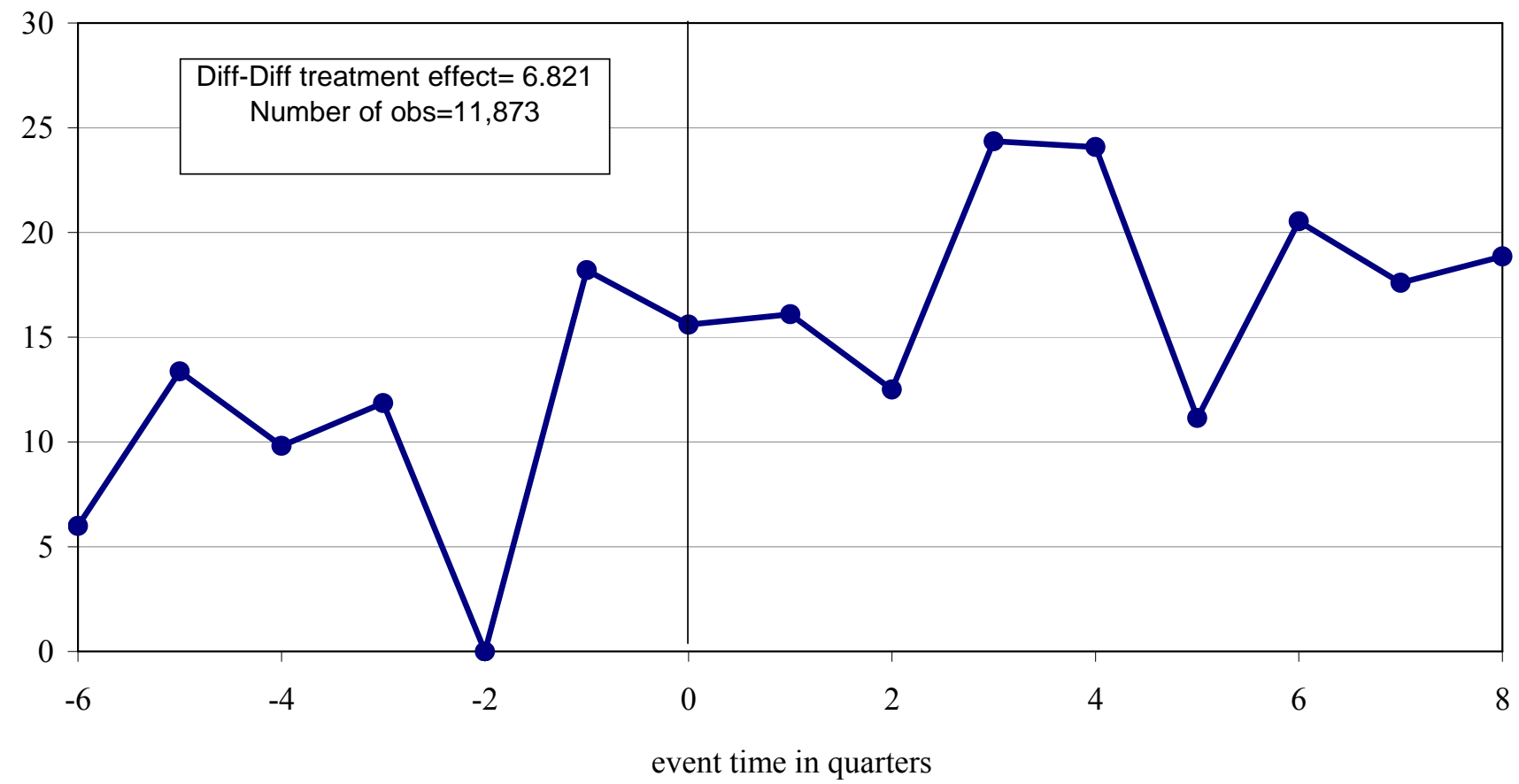

(b) Birth weight $<2,500$ grams

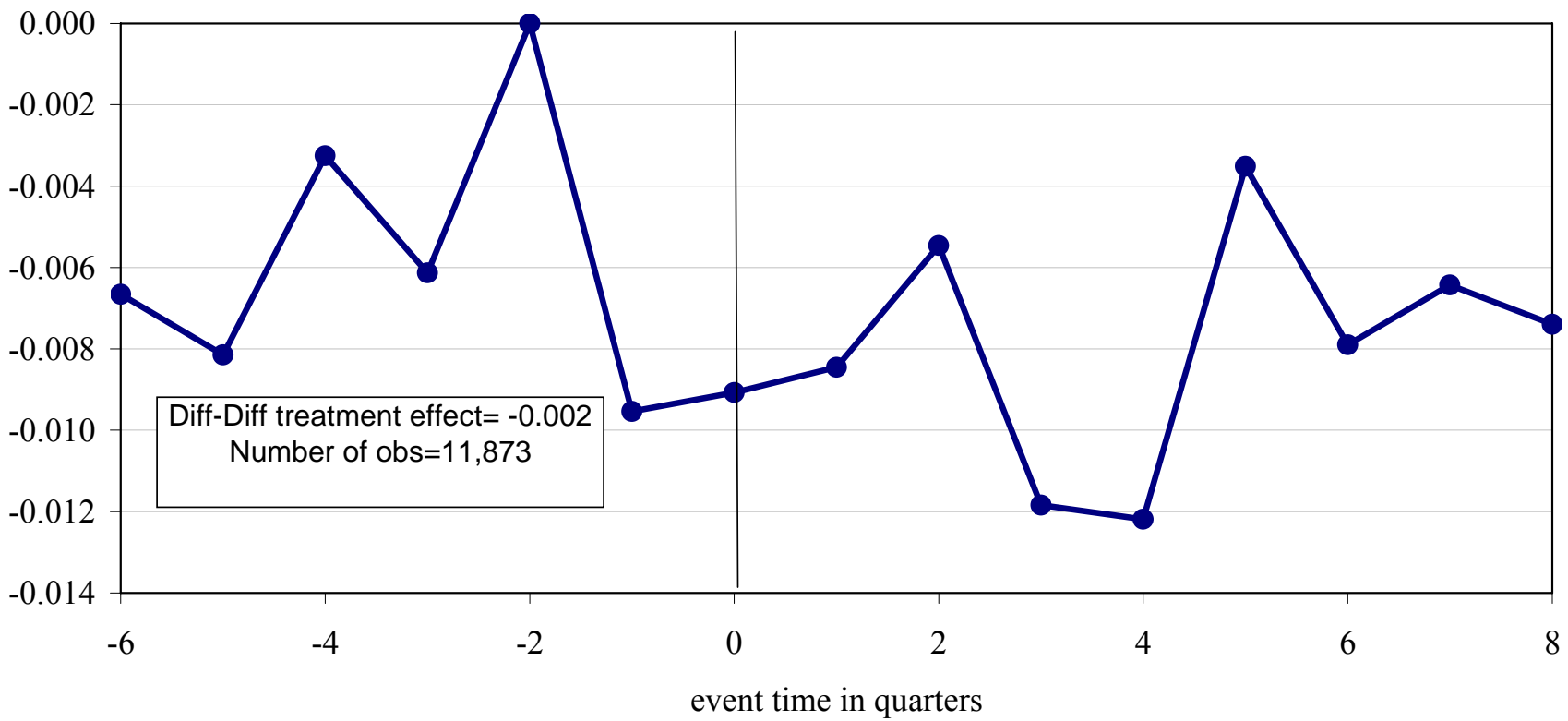

Notes: Each figure plots coefficients from an event-study analysis. Coefficients are defined as quarters relative to the quarter the Food Stamp Program is implemented in the county. The sample is a balanced county sample, where a county is included only if there are 6 quarters of preand 8 quarters of post- implementation data. The specification includes controls for county, county * linear time, quarter, 1960 county controls interacted with time, county per capita transfers and county real per capita income. 
Figure 7: Event Study Analysis for Whites

(a) Birth weight

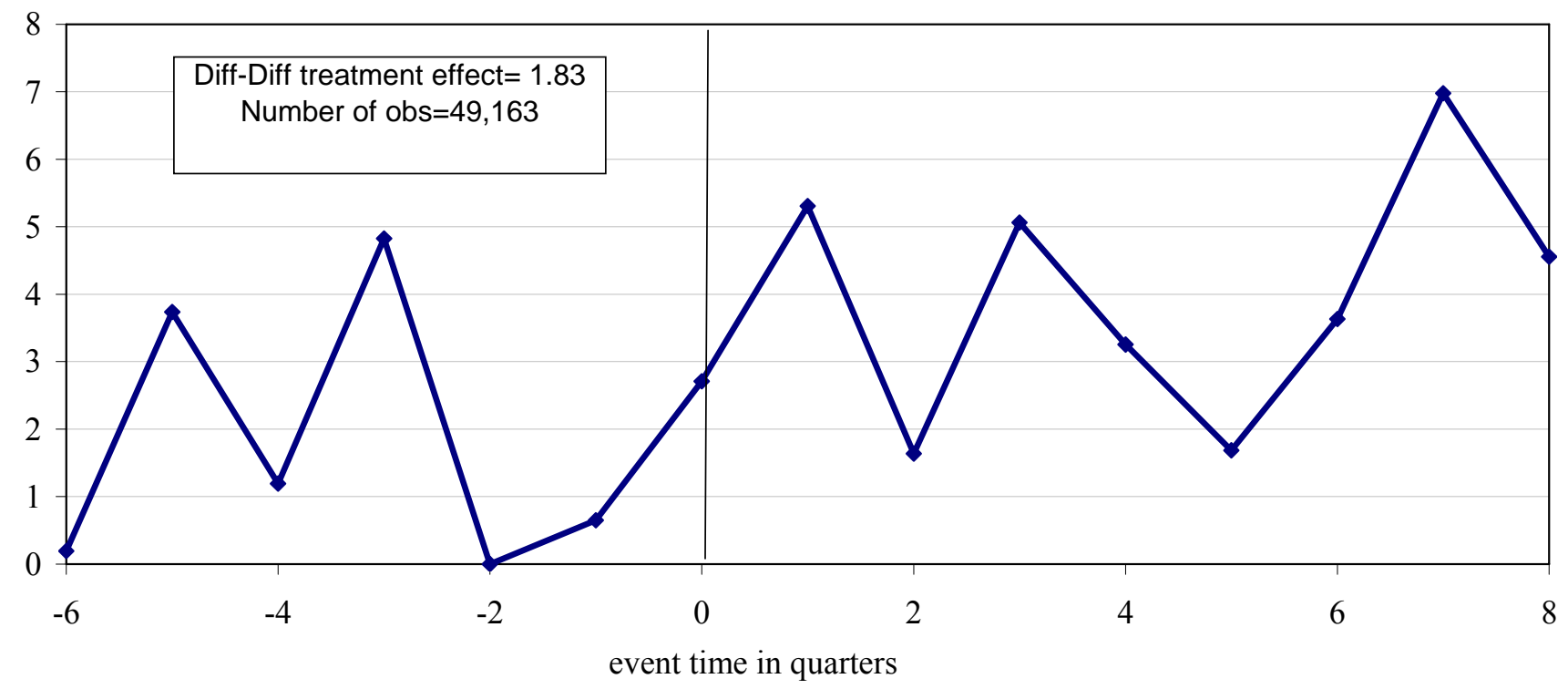

(b) Birth weight $<2,500$ grams

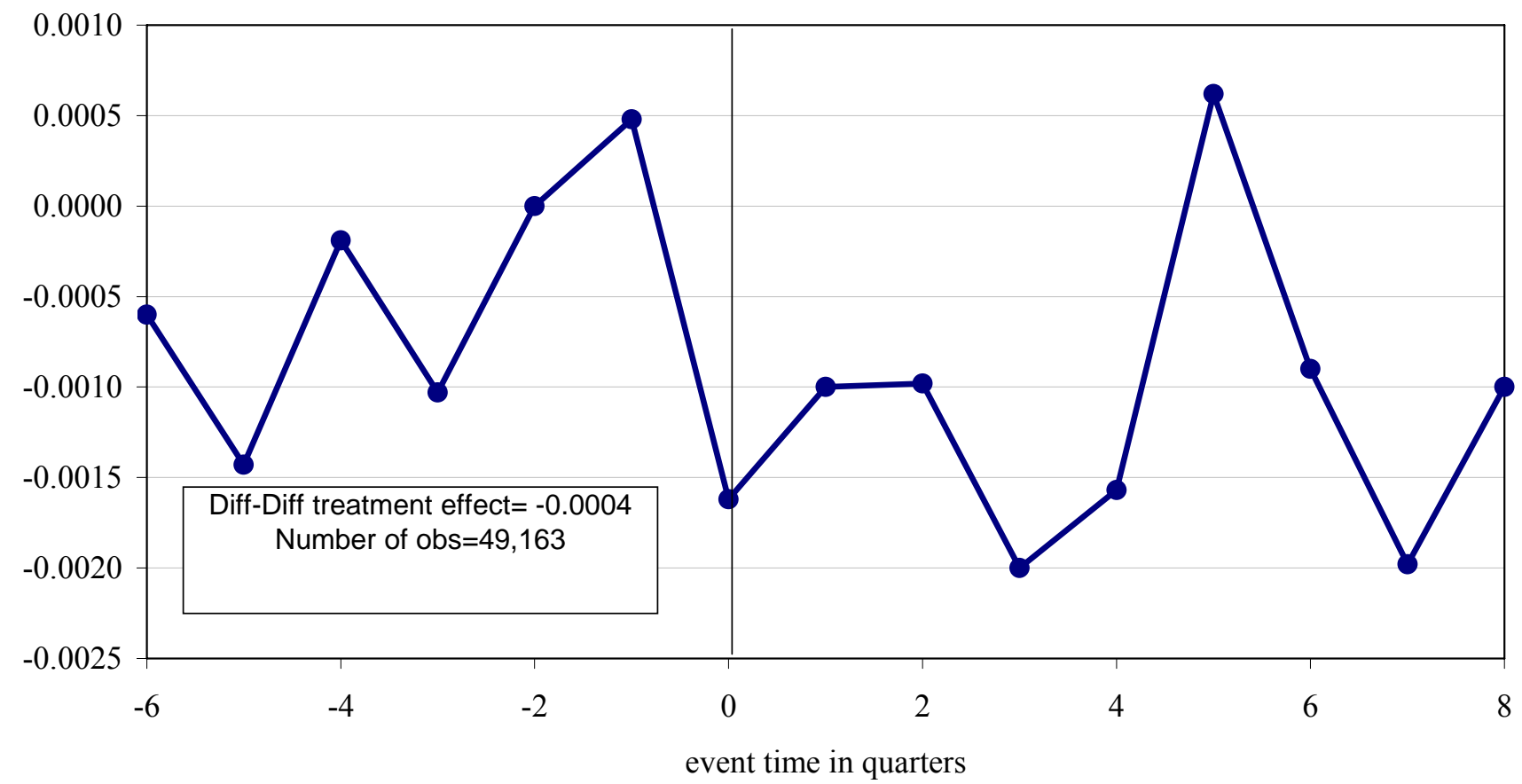

Notes: Each figure plots coefficients from an event-study analysis. Coefficients are defined as quarters relative to the quarter the Food Stamp Program is implemented in the county. The sample is a balanced county sample, where a county is included only if there are 6 quarters of preand 8 quarters of post- implementation data. The specification includes controls for county, county * linear time, quarter, 1960 county controls interacted with time, county per capita transfers and county real per capita income. 
Table 1A: Impacts of Food Stamp Introduction on Birth Outcomes, by Race

\begin{tabular}{|c|c|c|c|c|c|c|c|c|}
\hline & $\begin{array}{c}\text { Birthweight } \\
\text { (1) }\end{array}$ & $(2)$ & (3) & (4) & $\begin{array}{c}\text { Fraction }<2, \\
(5)\end{array}$ & $\begin{array}{r}0 \text { grams } \\
(6)\end{array}$ & (7) & $(8)$ \\
\hline \multicolumn{9}{|l|}{ A. WHITES } \\
\hline$\overline{\text { Ave FSP }(0 / 1)}$ & $\begin{array}{c}2.039 \\
(0.947)^{*}\end{array}$ & $\begin{array}{c}2.635 \\
(0.896)^{* *}\end{array}$ & $\begin{array}{c}2.089 \\
(1.039)^{*}\end{array}$ & $\begin{array}{c}2.175 \\
(0.975)^{* *}\end{array}$ & $\begin{array}{c}-0.0006 \\
(0.0003)^{*}\end{array}$ & $\begin{array}{c}-0.0006 \\
(0.0003)^{*}\end{array}$ & $\begin{array}{l}-0.0006 \\
(0.0003)\end{array}$ & $\begin{array}{l}-0.0006 \\
(0.0004)\end{array}$ \\
\hline$\%$ Impact (coef/mean) & $0.06 \%$ & $0.08 \%$ & $0.06 \%$ & $0.06 \%$ & $-1.02 \%$ & $-1.02 \%$ & $-0.97 \%$ & $-0.97 \%$ \\
\hline Estimate inflated & 15.68 & 20.27 & 16.07 & 16.73 & -0.0047 & -0.0047 & -0.0045 & 0.00 \\
\hline$\%$ Impact inflated & $0.47 \%$ & $0.61 \%$ & $0.48 \%$ & $0.50 \%$ & $-7.82 \%$ & $-7.82 \%$ & $-7.44 \%$ & $-7.44 \%$ \\
\hline \multicolumn{9}{|l|}{ B. BLACKS } \\
\hline Ave FSP $(0 / 1)$ & $\begin{array}{c}3.454 \\
(2.660)\end{array}$ & $\begin{array}{c}4.120 \\
(2.317)\end{array}$ & $\begin{array}{c}5.466 \\
(2.579)^{*}\end{array}$ & $\begin{array}{c}1.665 \\
(2.330)\end{array}$ & $\begin{array}{l}-0.0015 \\
(0.0010)\end{array}$ & $\begin{array}{l}-0.0016 \\
(0.0010)\end{array}$ & $\begin{array}{l}-0.0019 \\
(0.0012)\end{array}$ & $\begin{array}{l}-0.0009 \\
(0.0012)\end{array}$ \\
\hline Impact relative to mean & $0.11 \%$ & $0.13 \%$ & $0.18 \%$ & $0.05 \%$ & $-1.13 \%$ & $-1.22 \%$ & $-1.49 \%$ & $-0.68 \%$ \\
\hline Estimate inflated & 26.57 & 31.69 & 42.05 & 12.80 & -0.0113 & -0.0122 & -0.0149 & -0.01 \\
\hline$\%$ Impact inflated & $0.86 \%$ & $1.02 \%$ & $1.36 \%$ & $0.41 \%$ & $-8.70 \%$ & $-9.41 \%$ & $-11.48 \%$ & $-5.21 \%$ \\
\hline $1960 \mathrm{CCDB} *$ linear time & $\mathrm{x}$ & $\mathrm{x}$ & $\mathrm{x}$ & & $\mathrm{x}$ & $\mathrm{x}$ & $\mathrm{x}$ & \\
\hline REIS controls & $\mathrm{x}$ & $\mathrm{x}$ & $\mathrm{x}$ & $\mathrm{x}$ & $\mathrm{x}$ & $\mathrm{x}$ & $\mathrm{x}$ & $\mathrm{x}$ \\
\hline cty per cap real income & $\mathrm{x}$ & $\mathrm{x}$ & $\mathrm{x}$ & $\mathrm{x}$ & $\mathrm{x}$ & $\mathrm{x}$ & $\mathrm{x}$ & $\mathrm{x}$ \\
\hline yr x qtr fixed effects & $\mathrm{x}$ & $\mathrm{x}$ & $\mathrm{x}$ & $\mathrm{x}$ & $\mathrm{x}$ & $\mathrm{x}$ & $\mathrm{x}$ & $\mathrm{x}$ \\
\hline county fixed effects & $\mathrm{x}$ & $\mathrm{x}$ & $\mathrm{x}$ & $\mathrm{x}$ & $\mathrm{x}$ & $\mathrm{x}$ & $\mathrm{x}$ & $\mathrm{x}$ \\
\hline $\begin{array}{l}\text { state } * \text { linear time } \\
\text { state } * \text { year fixed effects }\end{array}$ & & $\mathrm{x}$ & $\mathrm{x}$ & & & $\mathrm{x}$ & $\mathrm{x}$ & \\
\hline county $*$ linear time & & & & $\mathrm{x}$ & & & & $\mathrm{x}$ \\
\hline Observations (whites) & 97785 & 97785 & 97785 & 97785 & 97785 & 97785 & 97785 & 97785 \\
\hline R-squared (whites) & 0.54 & 0.55 & 0.55 & 0.56 & 0.17 & 0.17 & 0.18 & 0.19 \\
\hline mean of dependant variable (whites) & 3350 & 3350 & 3350 & 3350 & 0.06 & 0.06 & 0.06 & 0.06 \\
\hline Observations (blacks) & 27374 & 27374 & 27374 & 27374 & 27374 & 27374 & 27374 & 27374 \\
\hline R-squared (blacks) & 0.32 & 0.33 & 0.34 & 0.35 & 0.15 & 0.15 & 0.17 & 0.18 \\
\hline mean of dependant variable (blacks) & 3097 & 3097 & 3097 & 3097 & 0.13 & 0.13 & 0.13 & 0.13 \\
\hline
\end{tabular}

Notes: Each parameter is from a separate regression of the outcome variable on the Food Stamp implementation dummy. The treatment is assigned as of 3 months prior to birth (proxy for beginning of the $3^{\text {rd }}$ trimester). The estimation sample includes means by race-county-quarter for years including $1968-1977$ where cells with less than 25 births are dropped. In addition to the fixed effects, controls include 1960 county variables (log of population, percent of land in farming, percent of population black, urban, age $<5$, age $>65$ and with income less than $\$ 3,000$ ) each interacted with a linear time trend, per capita county transfer income (public assistance, medical care, and retirement and disability benefits), and county real per capita income. Estimates are weighted using the number of births in the cell and are clustered on county. Standard errors are in parentheses. Inflated impacts divide the parameter estimate by an estimate of the food stamp participation rate for the regression sample. 
Table 1B: Impacts of Food Stamp Introduction on Birth Outcomes, by Race

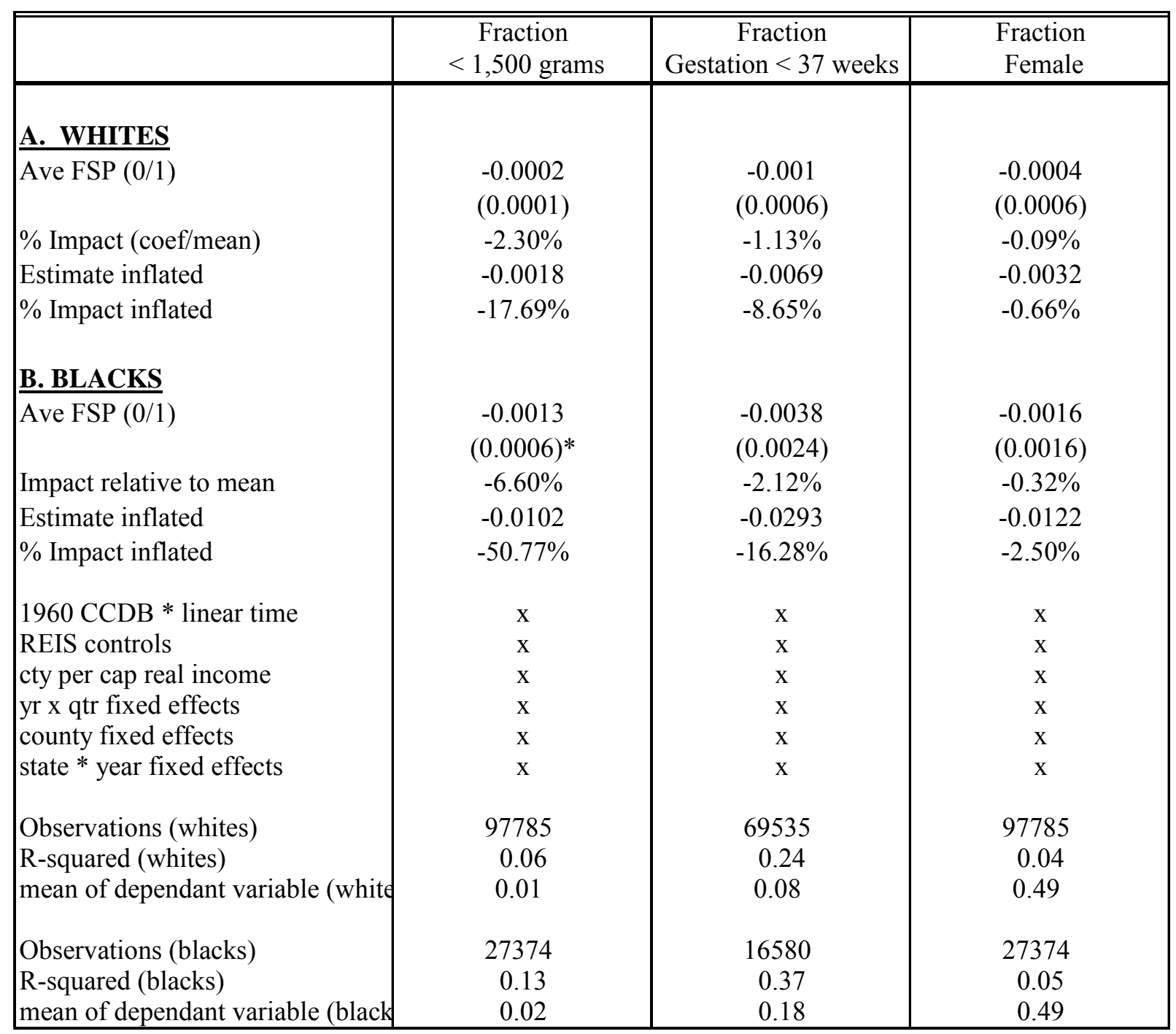

Notes: Each parameter is from a separate regression of the outcome variable on the Food Stamp implementation dummy. The treatment is assigned as of 3 months prior to birth (proxy for beginning of the $3^{\text {rd }}$ trimester). The estimation sample includes means by race-county-quarter for years including 1968-1977 where cells with less than 25 births are dropped. In addition to the fixed effects, controls include 1960 county variables (log of population, percent of land in farming, percent of population black, urban, age $<5$, age $>65$ and with income less than $\$ 3,000$ ) each interacted with a linear time trend, per capita county transfer income (public assistance, medical care, and retirement and disability benefits), and county real per capita income. Estimates are weighted using the number of births in the cell and are clustered on county. Standard errors are in parentheses. Inflated impacts divide the parameter estimate by an estimate of the food stamp participation rate for the regression sample. 
Table 2: Sensitivity to Changing Timing of Policy Introduction

\begin{tabular}{|c|c|c|c|c|c|}
\hline MAIN POLICY EFFECT: & $\begin{array}{l}\text { Birthweight } \\
\text { FSP-beg of } \\
\text { 3rd trimester }\end{array}$ & $\begin{array}{l}\text { FSP-beg of } \\
\text { 2nd trimester }\end{array}$ & $\begin{array}{l}\text { FSP-beg of } \\
1 \text { st trimester }\end{array}$ & $\begin{array}{l}\text { FSP-beg of } \\
\text { 3rd trimester }\end{array}$ & $\begin{array}{l}\text { FSP-beg of } \\
\text { 3rd trimester }\end{array}$ \\
\hline SECOND POLICY EFFECT: & $(--)$ & (-- & (3) & $\begin{array}{l}\text { FSP-beg of } \\
\text { 2nd trimester } \\
(4)\end{array}$ & $\begin{array}{l}\text { FSP-beg of } \\
1 \text { st trimester } \\
(5) \\
\end{array}$ \\
\hline$\frac{\text { A. WHITES }}{\text { Ave FSP }(0 / 1)}$ & $\begin{array}{c}2.085 \\
(1.020)^{* *}\end{array}$ & $\begin{array}{c}1.696 \\
(1.024)^{*}\end{array}$ & $\begin{array}{l}1.288 \\
(0.993)\end{array}$ & $\begin{array}{l}2.556 \\
(1.640)\end{array}$ & $\begin{array}{c}2.434 \\
(1.268)^{*}\end{array}$ \\
\hline $\begin{array}{l}\text { Ave FSP }(0 / 1) \\
\text { SECOND POLICY VAR }\end{array}$ & -- & -- & -- & $\begin{array}{l}-0.533 \\
(1.650)\end{array}$ & $\begin{array}{l}-0.454 \\
(1.232)\end{array}$ \\
\hline $\begin{array}{l}\text { Observations (whites) } \\
\text { R-squared (whites) } \\
\text { mean of dependant variable (white }\end{array}$ & $\begin{array}{c}97785 \\
0.55 \\
3350\end{array}$ & $\begin{array}{c}97785 \\
0.55 \\
3350\end{array}$ & $\begin{array}{c}97785 \\
0.55 \\
3350\end{array}$ & $\begin{array}{c}97785 \\
0.55 \\
3350\end{array}$ & $\begin{array}{c}97785 \\
0.55 \\
3350\end{array}$ \\
\hline$\frac{\text { B. BLACKS }}{\text { Ave FSP }(0 / 1)}$ & $\begin{array}{c}5.447 \\
(2.532)^{* *}\end{array}$ & $\begin{array}{c}4.704 \\
(2.464)^{*}\end{array}$ & $\begin{array}{l}2.071 \\
(2.396)\end{array}$ & $\begin{array}{c}5.334 \\
(4.596)\end{array}$ & $\begin{array}{c}8.108 \\
(3.444)^{* *}\end{array}$ \\
\hline $\begin{array}{l}\text { Ave FSP }(0 / 1) \\
\text { SECOND POLICY VAR }\end{array}$ & -- & -- & -- & $\begin{array}{c}0.130 \\
(4.450)\end{array}$ & $\begin{array}{l}-3.515 \\
(3.268)\end{array}$ \\
\hline $\begin{array}{l}\text { Observations (blacks) } \\
\text { R-squared (blacks) } \\
\text { mean of dependant variable (black }\end{array}$ & $\begin{array}{c}27374 \\
0.34 \\
3097\end{array}$ & $\begin{array}{c}27374 \\
0.34 \\
3097\end{array}$ & $\begin{array}{c}27374 \\
0.34 \\
3097\end{array}$ & $\begin{array}{c}27374 \\
0.34 \\
3097\end{array}$ & $\begin{array}{c}27374 \\
0.34 \\
3097\end{array}$ \\
\hline $\begin{array}{l}1960 \text { CCDB * linear time } \\
\text { REIS controls } \\
\text { cty per cap real income } \\
\text { yr x qtr fixed effects } \\
\text { county fixed effects } \\
\text { state * year fixed effects }\end{array}$ & $\begin{array}{l}\mathrm{x} \\
\mathrm{x} \\
\mathrm{x} \\
\mathrm{x} \\
\mathrm{x} \\
\mathrm{x}\end{array}$ & $\begin{array}{l}\mathrm{x} \\
\mathrm{x} \\
\mathrm{x} \\
\mathrm{x} \\
\mathrm{x} \\
\mathrm{x}\end{array}$ & $\begin{array}{l}\mathrm{x} \\
\mathrm{x} \\
\mathrm{x} \\
\mathrm{x} \\
\mathrm{x} \\
\mathrm{x}\end{array}$ & $\begin{array}{l}\mathrm{x} \\
\mathrm{x} \\
\mathrm{x} \\
\mathrm{x} \\
\mathrm{x} \\
\mathrm{x}\end{array}$ & $\begin{array}{l}\mathrm{x} \\
\mathrm{x} \\
\mathrm{x} \\
\mathrm{x} \\
\mathrm{x} \\
\mathrm{x}\end{array}$ \\
\hline
\end{tabular}

Notes: Each parameter is from a separate regression of the outcome variable on the Food Stamp implementation dummy. The specifications vary by changing the timing of food stamp implementation. Base case is in column 1 where the timing is as of three months prior to the birth (to proxy for beginning of the $3^{\text {rd }}$ trimester). The alternative specifications include timing as of 6 months $\left(2^{\text {nd }}\right.$ trimester $)$ or 9 months $\left(1^{\text {st }}\right.$ trimester $)$ prior ro birth. In specifications (4) we estimate jointly the treatment effects at the $3^{\text {rd }}$ and $2^{\text {nd }}$ trimesters and in (5) we estimate jointly the impacts measured at the $3^{\text {rd }}$ and $1^{\text {st }}$ trimester. All of the other control variables and sample definitions are described in the notes to table 1 . 
Table 3: Sensitivity of Estimates to Including One Year Lead of Policy Variable

\begin{tabular}{|c|c|c|c|c|c|}
\hline & $\begin{array}{c}\text { Birthweight } \\
\text { (1) }\end{array}$ & $\begin{array}{l}\mathrm{LBW} \\
(2)\end{array}$ & $\begin{array}{l}\text { VLBW } \\
\text { (3) }\end{array}$ & $\begin{array}{c}\text { GEST< }<37 \\
(4)\end{array}$ & $\begin{array}{c}\% \text { Female } \\
\text { (5) }\end{array}$ \\
\hline \multicolumn{6}{|l|}{ A. WHITES } \\
\hline Ave $\operatorname{FSP}(0 / 1)$ & $\begin{array}{c}2.161 \\
(1.038)^{* *}\end{array}$ & $\begin{array}{l}-0.0005 \\
(0.0004)\end{array}$ & $\begin{array}{l}-0.0002 \\
(0.0002)\end{array}$ & $\begin{array}{c}-0.0019 \\
(0.0007)^{* *}\end{array}$ & $\begin{array}{l}-0.0003 \\
(0.0007)\end{array}$ \\
\hline One Year Lead of Ave FSP (0/1) & $\begin{array}{l}-0.159 \\
(1.226)\end{array}$ & $\begin{array}{l}-0.0002 \\
(0.0004)\end{array}$ & $\begin{array}{c}0.0000 \\
(0.0002)\end{array}$ & $\begin{array}{c}0.0015 \\
(0.0008)^{*}\end{array}$ & $\begin{array}{l}-0.0002 \\
(0.0008)\end{array}$ \\
\hline \multicolumn{6}{|l|}{ B. BLACKS } \\
\hline Ave FSP $(0 / 1)$ & $\begin{array}{c}6.369 \\
(2.681)^{* *}\end{array}$ & $\begin{array}{l}-0.0026 \\
(0.001)^{*}\end{array}$ & $\begin{array}{l}-0.0011 \\
(0.0007)\end{array}$ & $\begin{array}{l}-0.0003 \\
(0.0027)\end{array}$ & $\begin{array}{c}-0.0001 \\
(0.0019)\end{array}$ \\
\hline One Year Lead of Ave FSP (0/1) & $\begin{array}{l}-1.980 \\
(3.356)\end{array}$ & $\begin{array}{c}0.0015 \\
(0.0014)\end{array}$ & $\begin{array}{l}-0.0005 \\
(0.0007)\end{array}$ & $\begin{array}{l}-0.0023 \\
(0.0033)\end{array}$ & $\begin{array}{l}-0.0033 \\
(0.0022)\end{array}$ \\
\hline $1960 \mathrm{CCDB} *$ linear time & $\mathrm{x}$ & $\mathrm{x}$ & $\mathrm{x}$ & $\mathrm{x}$ & $\mathrm{x}$ \\
\hline REIS controls & $\mathrm{x}$ & $\mathrm{x}$ & $\mathrm{x}$ & $\mathrm{x}$ & $\mathrm{x}$ \\
\hline cty per cap real income & $\mathrm{x}$ & $\mathrm{x}$ & $\mathrm{x}$ & $\mathrm{x}$ & $\mathrm{x}$ \\
\hline yr x qtr fixed effects & $\mathrm{x}$ & $\mathrm{x}$ & $\mathrm{x}$ & $\mathrm{x}$ & $\mathrm{x}$ \\
\hline county fixed effects & $\mathrm{x}$ & $\mathrm{x}$ & $\mathrm{x}$ & $\mathrm{x}$ & $\mathrm{x}$ \\
\hline state $*$ year fixed effects & $\mathrm{x}$ & $\mathrm{x}$ & $\mathrm{x}$ & $\mathrm{x}$ & $\mathrm{x}$ \\
\hline Observations (whites) & 97785 & 97785 & 97785 & 66888 & 97785 \\
\hline R-squared (whites) & 0.55 & 0.18 & 0.06 & 0.15 & 0.04 \\
\hline mean of dependant variable (whites & 3350 & 0.06 & 0.01 & 0.08 & 0.49 \\
\hline Observations (blacks) & 27374 & 27374 & 27374 & 15777 & 27374 \\
\hline R-squared (blacks) & 0.34 & 0.17 & 0.13 & 0.24 & 0.05 \\
\hline mean of dependant variable (blacks & 3097 & 0.13 & 0.02 & 0.18 & 0.49 \\
\hline
\end{tabular}

Notes: Each parameter is from a separate regression of the outcome variable on the Food Stamp implementation dummy. There are two treatment variables: the baseline treatment is assigned as of the month of birth and a one year lead of that policy variable. The estimation sample includes means by race-county-quarter for years including 19681977 where cells with less than 25 births are dropped. Controls include county, year * quarter and state * year fixed effects, 1960 county variables (log of population, percent of land in farming, percent of population black, urban, age $<5$, age $>65$ and with income less than $\$ 3,000$ ) each interacted with a linear time trend, per capita county transfer income (public assistance, medical care, and retirement and disability benefits), and county real per capita income. Estimates are weighted using the number of births in the cell and are clustered on county. Standard errors are in parentheses. Inflated impacts divide the parameter estimate by an estimate of the food stamp participation rate for the regression sample. 
Table 4: Impact of FSP Introduction on Infant Outcomes, by Quartiles of Poverty

\begin{tabular}{|c|c|c|c|c|}
\hline & \multicolumn{2}{|c|}{$\begin{array}{c}\text { QUARTILE 1 (LOW FSP } \\
\text { COUNTIES) }\end{array}$} & \multicolumn{2}{|c|}{$\begin{array}{c}\text { QUARTILE } 4 \text { (HIGH FSP } \\
\text { COUNTIES) }\end{array}$} \\
\hline & $\begin{array}{l}\text { Birthweight } \\
\text { (1) }\end{array}$ & $\begin{array}{l}\mathrm{LBW} \\
(2)\end{array}$ & $\begin{array}{l}\text { Birthweight } \\
\text { (3) }\end{array}$ & $\begin{array}{c}\text { LBW } \\
(4)\end{array}$ \\
\hline \multicolumn{5}{|l|}{ A. WHITES } \\
\hline$\overline{A v e ~ F S P ~(0 / 1) ~}$ & $\begin{array}{l}-0.3107 \\
(1.5348)\end{array}$ & $\begin{array}{c}0.0001 \\
(0.0005)\end{array}$ & $\begin{array}{l}1.0756 \\
(2.8287)\end{array}$ & $\begin{array}{l}-0.0001 \\
(0.0009)\end{array}$ \\
\hline$\%$ Impact (coef/mean) & $-0.01 \%$ & $0.15 \%$ & $0.03 \%$ & $-0.16 \%$ \\
\hline \multicolumn{5}{|l|}{ B. BLACKS } \\
\hline$\overline{\operatorname{Ave} F S P(0 / 1)}$ & $\begin{array}{l}-3.5676 \\
(8.4366)\end{array}$ & $\begin{array}{c}0.0045 \\
(0.0042)\end{array}$ & $\begin{array}{c}2.2071 \\
(4.2195)\end{array}$ & $\begin{array}{l}-0.0007 \\
(0.0017)\end{array}$ \\
\hline$\%$ Impact (coef/mean) & $-0.12 \%$ & $3.42 \%$ & $0.07 \%$ & $-0.52 \%$ \\
\hline $1960 \mathrm{CCDB} *$ linear time & $\mathrm{x}$ & $\mathrm{x}$ & $\mathrm{x}$ & $\mathrm{x}$ \\
\hline REIS controls & $\mathrm{x}$ & $\mathrm{x}$ & $\mathrm{x}$ & $\mathrm{x}$ \\
\hline cty per cap real income & $\mathrm{x}$ & $\mathrm{x}$ & $\mathrm{x}$ & $\mathrm{x}$ \\
\hline yr x qtr fixed effects & $\mathrm{x}$ & $\mathrm{x}$ & $\mathrm{x}$ & $\mathrm{x}$ \\
\hline county fixed effects & $\mathrm{x}$ & $\mathrm{x}$ & $\mathrm{x}$ & $\mathrm{x}$ \\
\hline state * year fixed effects & $\mathrm{x}$ & $\mathrm{x}$ & $\mathrm{x}$ & $\mathrm{x}$ \\
\hline Observations (whites) & 34668 & 34668 & 21819 & 21819 \\
\hline R-squared (whites) & 0.51 & 0.16 & 0.58 & 0.20 \\
\hline mean of dependant variable (white & 3364.67 & 0.06 & 3337.05 & 0.07 \\
\hline Observations (blacks) & 3163 & 3163 & 11773 & 11773 \\
\hline R-squared (blacks) & 0.26 & 0.17 & 0.43 & 0.20 \\
\hline mean of dependant variable (black & 3081.55 & 0.13 & 3117.55 & 0.13 \\
\hline
\end{tabular}

Notes: Each parameter is from a separate regression of the outcome variable on the Food Stamp implementation dummy. The treatment is assigned as of 3 months prior to birth. The estimation sample includes means by countyquarter for years including 1968-1977 where cells with less than 25 births are dropped. Controls include county, year * quarter and state * year fixed effects, 1960 county variables (log of population, percent of land in farming, percent of population black, urban, age $<5$, age $>65$ and with income less than $\$ 3,000$ ) each interacted with a linear time trend, per capita county transfer income (public assistance, medical care, and retirement and disability benefits), and county real per capita income. Estimates are weighted using the number of births in the cell and are clustered on county. Standard errors are in parentheses. Inflated impacts divide the parameter estimate by an estimate of the food stamp participation rate for the regression sample. Quartiles are assigned using 1978 county per capita food stamp payments from the REIS. 
Table 5: Impacts of FSP Introduction on Birth Outcomes, by Geography

\begin{tabular}{|c|c|c|c|c|c|c|c|c|}
\hline & \multicolumn{2}{|c|}{ SOUTH } & \multicolumn{2}{|c|}{ NONSOUTH } & \multicolumn{2}{|c|}{ URBAN COUNTIES } & \multicolumn{2}{|c|}{ NONURBAN COUNTIES } \\
\hline & $\begin{array}{c}\text { Birthweight } \\
\text { (1) }\end{array}$ & $\begin{array}{l}\text { LBW } \\
(2)\end{array}$ & $\begin{array}{c}\text { Birthweight } \\
\text { (3) }\end{array}$ & $\begin{array}{c}\text { LBW } \\
(4)\end{array}$ & $\begin{array}{c}\text { Birthweight } \\
\text { (5) }\end{array}$ & $\begin{array}{c}\text { LBW } \\
(6)\end{array}$ & $\begin{array}{c}\text { Birthweight } \\
\text { (7) }\end{array}$ & $\begin{array}{c}\text { LBW } \\
(8)\end{array}$ \\
\hline A. WHITES & & & & & & & & \\
\hline Ave FSP (0/1) & $\begin{array}{c}2.403 \\
(1.612)\end{array}$ & $\begin{array}{c}-0.0011 \\
(0.0005)^{* *}\end{array}$ & $\begin{array}{c}1.771 \\
(1.322)\end{array}$ & $\begin{array}{l}-0.0003 \\
(0.0004)\end{array}$ & $\begin{array}{c}2.364 \\
(1.247)^{*}\end{array}$ & $\begin{array}{c}-0.0008 \\
(0.0004)^{* *}\end{array}$ & $\begin{array}{c}0.508 \\
(1.615)\end{array}$ & $\begin{array}{c}-0.0002 \\
(0.0006)\end{array}$ \\
\hline $\begin{array}{l}\% \text { Impact (coef/mean) } \\
\text { B. BLACKS }\end{array}$ & $0.07 \%$ & $-1.57 \%$ & $0.05 \%$ & $-0.48 \%$ & $0.07 \%$ & $-1.13 \%$ & $0.02 \%$ & $-0.25 \%$ \\
\hline Ave FSP (0/1) & $\begin{array}{c}3.527 \\
(3.134)\end{array}$ & $\begin{array}{c}-0.0023 \\
(0.0014)^{*}\end{array}$ & $\begin{array}{c}7.003 \\
(3.992)^{*}\end{array}$ & $\begin{array}{l}-0.0009 \\
(0.0022)\end{array}$ & $\begin{array}{c}8.371 \\
(2.846)^{* *}\end{array}$ & $\begin{array}{c}-0.0034 \\
(0.0013)^{* *}\end{array}$ & $\begin{array}{l}-0.745 \\
(5.219)\end{array}$ & $\begin{array}{c}0.0023 \\
(0.0023)\end{array}$ \\
\hline$\%$ Impact (coef/mean) & $0.11 \%$ & $-1.76 \%$ & $0.23 \%$ & $-0.69 \%$ & $0.27 \%$ & $-2.59 \%$ & $-0.02 \%$ & $1.74 \%$ \\
\hline $1960 \mathrm{CCDB} *$ linear time & $\mathrm{x}$ & $\mathrm{x}$ & $\mathrm{x}$ & $\mathrm{x}$ & $\mathrm{x}$ & $\mathrm{x}$ & $\mathrm{x}$ & $\mathrm{x}$ \\
\hline REIS controls & $\mathrm{x}$ & $\mathrm{x}$ & $x$ & $x$ & $x$ & $\mathrm{x}$ & $\mathrm{x}$ & $\mathrm{x}$ \\
\hline cty per cap real income & $\mathrm{x}$ & $\mathrm{x}$ & $\mathrm{x}$ & $\mathrm{x}$ & $\mathrm{x}$ & $\mathrm{x}$ & $\mathrm{x}$ & $\mathrm{x}$ \\
\hline yr x qtr fixed effects & $\mathrm{x}$ & $\mathrm{x}$ & $\mathrm{x}$ & $\mathrm{x}$ & $\mathrm{x}$ & $\mathrm{x}$ & $\mathrm{x}$ & $\mathrm{x}$ \\
\hline county fixed effects & $\mathrm{x}$ & $\mathrm{x}$ & $\mathrm{x}$ & $\mathrm{x}$ & $\mathrm{x}$ & $\mathrm{x}$ & $\mathrm{x}$ & $\mathrm{x}$ \\
\hline state $*$ year fixed effects & $\mathrm{x}$ & $\mathrm{x}$ & $\mathrm{x}$ & $\mathrm{x}$ & $\mathrm{x}$ & $\mathrm{x}$ & $\mathrm{x}$ & $\mathrm{x}$ \\
\hline Observations (whites) & 44194 & 44194 & 53591 & 53591 & 32282 & 32282 & 65503 & 65503 \\
\hline Subsample Population (whites) & 0.29 & 0.29 & 0.69 & 0.69 & 0.73 & 0.73 & 0.25 & 0.25 \\
\hline Observations (blacks) & 20837 & 20837 & 6537 & 6537 & 13090 & 13090 & 14284 & 14284 \\
\hline Subsample Population (blacks) & 0.49 & 0.49 & 0.45 & 0.45 & 0.77 & 0.77 & 0.17 & 0.17 \\
\hline
\end{tabular}

Notes: Each parameter is from a separate regression of the outcome variable on the Food Stamp implementation dummy. The treatment is assigned as of the 3 months prior to birth. The estimation sample includes means by county-quarter for years including 1968-1977 where cells with less than 25 births are dropped. Controls include county, year * quarter and state * year fixed effects, 1960 county variables (log of population, percent of land in farming, percent of population black, urban, age $<5$, age $>65$ and with income less than $\$ 3,000$ ) each interacted with a linear time trend, per capita county transfer income (public assistance, medical care, and retirement and disability benefits), and county real per capita income. Estimates are weighted using the number of births in the cell and are clustered on county. Standard errors are in parentheses. Inflated impacts divide the parameter estimate by an estimate of the food stamp participation rate for the regression sample. Subsample population reports the percent of total births that are included in the regression. Urban counties are defined as those with greater than 50 percent of the 1960 population lives in an urban area. 
Table 6: Impact of FSP Introduction on Birth Location

\begin{tabular}{|l|c|c|}
\hline \hline & $\begin{array}{c}\text { Fraction births in } \\
\text { hospital } \\
(1)\end{array}$ & $\begin{array}{c}\text { Fraction births in } \\
\text { hospital or physicial } \\
\text { attending } \\
(2)\end{array}$ \\
\hline A. WHITES & 0.0012 & \\
\hline Ave FSP (0/1) & $(0.0009)$ & 0.0010 \\
B. BLACKS & & $(0.0009)$ \\
\hline Ave FSP (0/1) & -0.0018 & \\
& $(0.0030)$ & 0.0000 \\
1960 CCDB * linear time & & $(0.0030)$ \\
REIS controls & $\mathrm{x}$ & $\mathrm{x}$ \\
cty per cap real income & $\mathrm{x}$ & $\mathrm{x}$ \\
yr x qtr fixed effects & $\mathrm{x}$ & $\mathrm{x}$ \\
county fixed effects & $\mathrm{x}$ & $\mathrm{x}$ \\
state * year fixed effects & $\mathrm{x}$ & $\mathrm{x}$ \\
& $\mathrm{x}$ & $\mathrm{x}$ \\
Observations (whites) & 97785 & 97785 \\
R-squared (whites) & 0.73 & 0.80 \\
mean of dependant variable (whitg & 0.99 & 1.00 \\
& & \\
Observations (blacks) & 27374 & 27374 \\
R-squared (blacks) & 0.77 & 0.79 \\
mean of dependant variable (black & 0.94 & 0.95 \\
\hline
\end{tabular}

Notes: Each parameter is from a separate regression of the outcome variable on the Food Stamp implementation dummy. The treatment is assigned as of three months prior to birth. The estimation sample includes means by county-quarter for years including 1968-1977 where cells with less than 25 births are dropped. Controls include county, year * quarter and state * year fixed effects, 1960 county variables (log of population, percent of land in farming, percent of population black, urban, age $<5$, age $>65$ and with income less than $\$ 3,000$ ) each interacted with a linear time trend, per capita county transfer income (public assistance, medical care, and retirement and disability benefits), and county real per capita income. Estimates are weighted using the number of births in the cell and are clustered on county. Standard errors are in parentheses. 
Table 7: Impact of FSP Introduction on Fertility Rate (Births per 1000 women 15-44)

\begin{tabular}{|c|c|c|c|c|c|}
\hline & \multicolumn{5}{|c|}{ FSP implemented as of $\mathrm{X}$ quarters prior to birth } \\
\hline & $\begin{array}{l}3 \text { qtrs } \\
\text { (1) }\end{array}$ & $\begin{array}{c}4 \text { qtrs } \\
\text { (2) }\end{array}$ & $\begin{array}{c}5 \text { qtrs } \\
\text { (3) }\end{array}$ & $\begin{array}{c}6 \text { qtrs } \\
(4)\end{array}$ & $\begin{array}{l}7 \text { qtrs } \\
\text { (5) }\end{array}$ \\
\hline A. WHITES & 0.013 & -0.004 & 0.007 & 0.031 & 0.035 \\
\hline Ave FSP $(0 / 1)$ & $(0.078)$ & $(0.074)$ & $(0.071)$ & $(0.074)$ & $(0.070)$ \\
\hline$\%$ Impact (coef/mean) & $0.06 \%$ & $-0.02 \%$ & $0.04 \%$ & $0.16 \%$ & $0.18 \%$ \\
\hline$\%$ Impact, inflated & $0.50 \%$ & $-0.14 \%$ & $0.28 \%$ & $1.22 \%$ & $1.40 \%$ \\
\hline B. BLACKS & 0.211 & 0.157 & 0.276 & 0.307 & 0.227 \\
\hline Ave FSP $(0 / 1)$ & $(0.221)$ & $(0.206)$ & $(0.193)$ & $(0.190)$ & $(0.183)$ \\
\hline$\%$ Impact (coef/mean) & $0.80 \%$ & $0.60 \%$ & $1.05 \%$ & $1.17 \%$ & $0.86 \%$ \\
\hline$\%$ Impact, inflated & $1.75 \%$ & $1.30 \%$ & $2.29 \%$ & $2.54 \%$ & $1.88 \%$ \\
\hline $1960 \mathrm{CCDB} *$ linear time & $\mathrm{x}$ & $\mathrm{x}$ & $\mathrm{x}$ & $\mathrm{x}$ & $\mathrm{x}$ \\
\hline REIS controls & $\mathrm{x}$ & $\mathrm{x}$ & $\mathrm{x}$ & $\mathrm{x}$ & $\mathrm{x}$ \\
\hline cty per cap real income & $\mathrm{x}$ & $\mathrm{x}$ & $\mathrm{x}$ & $\mathrm{x}$ & $\mathrm{x}$ \\
\hline yr x qtr fixed effects & $\mathrm{x}$ & $\mathrm{x}$ & $\mathrm{x}$ & $\mathrm{x}$ & $\mathrm{x}$ \\
\hline county fixed effects & $\mathrm{x}$ & $\mathrm{x}$ & $\mathrm{x}$ & $\mathrm{x}$ & $\mathrm{x}$ \\
\hline state * year fixed effects & $\mathrm{x}$ & $\mathrm{x}$ & $\mathrm{x}$ & $\mathrm{x}$ & $\mathrm{x}$ \\
\hline Observations (whites) & 120293 & 120293 & 120293 & 120293 & 120293 \\
\hline mean of dependant variable (white & 19.40 & 19.40 & 19.40 & 19.40 & 19.40 \\
\hline Observations (blacks) & 44044 & 44044 & 44044 & 44044 & 44044 \\
\hline mean of dependant variable (black & 26.24 & 26.24 & 26.24 & 26.24 & 26.24 \\
\hline
\end{tabular}

Notes: Each parameter is from a separate regression of the outcome variable on the Food Stamp implementation dummy. The columns vary by the timing of the FSP implementation. The estimation sample includes means by racecounty-quarter for years including 1968-1977. Controls include county, year * quarter and state * year fixed effects, 1960 county variables (log of population, percent of land in farming, percent of population black, urban, age $<5$, age $>65$ and with income less than $\$ 3,000$ ) each interacted with a linear time trend, per capita county transfer income (public assistance, medical care, and retirement and disability benefits), and county real per capita income. Estimates are weighted using the population in the cell and are clustered on county. Standard errors are in parentheses. Inflated impacts divide the parameter estimate by an estimate of the food stamp participation rate for the regression sample. 
Table 8: Impact of FSP on Neonatal Infant Mortality Rate (Deaths per 1000 live births)

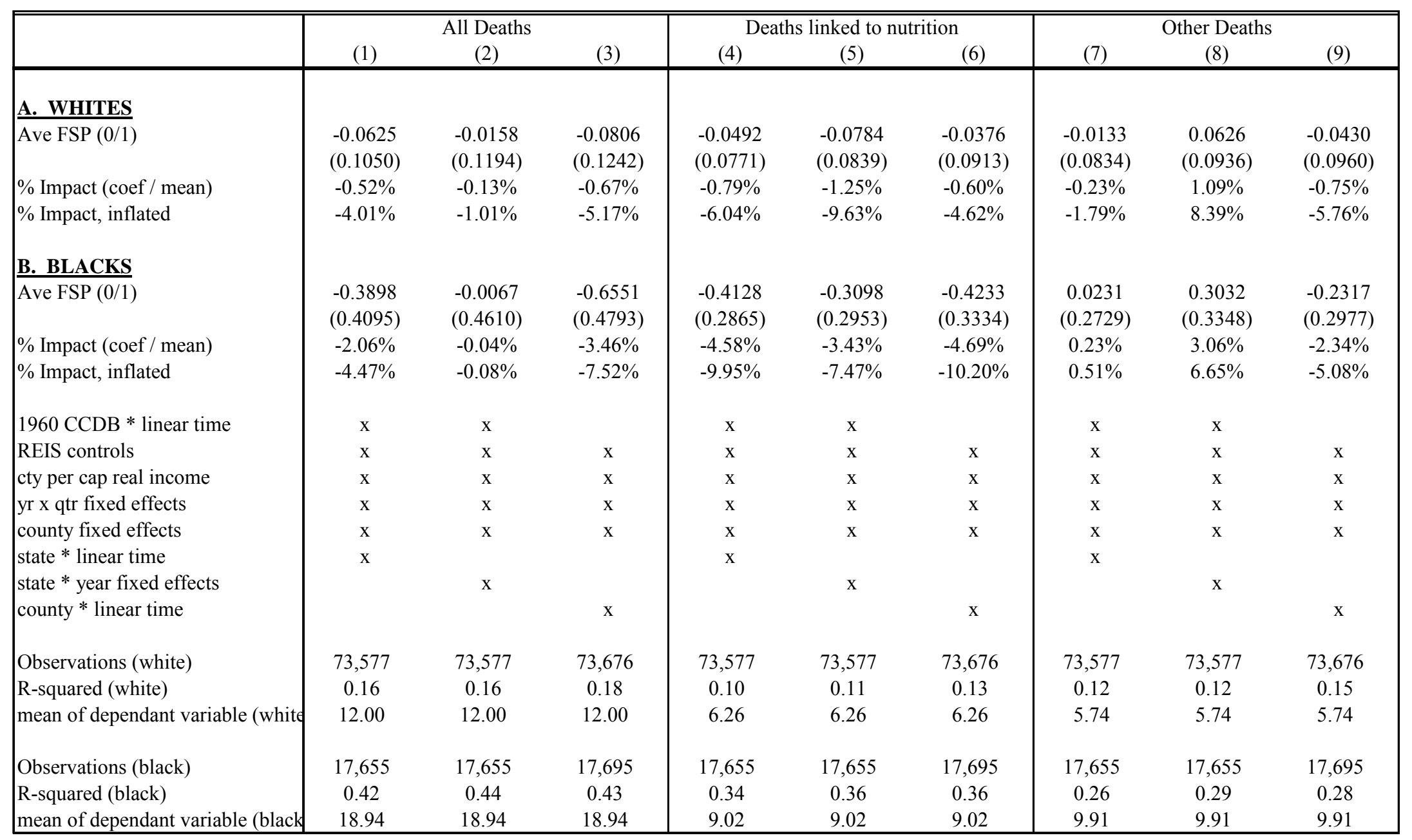

Notes: Each parameter is from a separate regression of the neonatal infant mortality rate (deaths in first 28 days per 1000 live births) on the FS implementation. The treatment is assigned as of 3 months prior to birth (proxy for beginning of the $3^{\text {rd }}$ trimester). The sample includes means by race-county-quarter for years including 1968-1977 where cells with less than 50 births are dropped. In addition to the fixed effects, controls include 1960 county variables (log of population, percent of land in farming, percent of population black, urban, age $<5$, age $>65$ and with income less than $\$ 3,000$ ) each interacted with a linear time trend, per capita county transfer income (public assistance, medical care, and retirement and disability benefits), and county real per capita income. Estimates are weighted using the number of births in the cell and are clustered on county. Standard errors are in parentheses. Inflated impacts divide the parameter estimate by an estimate of the food stamp participation rate for the regression sample. 
Table 9: Impact of FSP Introduction on Infant Mortality, Expanded Sample 1959+

\begin{tabular}{|c|c|c|c|c|c|c|c|c|c|}
\hline & \multicolumn{3}{|c|}{ "Original data (1968-1977) } & \multicolumn{3}{|c|}{ Full Period (1959-1977) } & \multicolumn{3}{|c|}{ Post pilot period (1964-77) } \\
\hline & $\begin{array}{l}\text { All } \\
(1)\end{array}$ & $\begin{array}{c}\text { Nutritiona } \\
\text { (2) }\end{array}$ & $\begin{array}{l}\text { Other } \\
\text { (3) }\end{array}$ & $\begin{array}{l}\text { All } \\
(4)\end{array}$ & $\begin{array}{c}\text { Nutritional } \\
\text { (5) }\end{array}$ & $\begin{array}{l}\text { Other } \\
(6)\end{array}$ & $\begin{array}{l}\text { All } \\
(7)\end{array}$ & $\begin{array}{c}\text { Nutritiona } \\
(8)\end{array}$ & $\begin{array}{l}\text { Other } \\
(9)\end{array}$ \\
\hline \multicolumn{10}{|l|}{ All Races } \\
\hline Ave FSP $(0 / 1)$ & -0.197 & -0.116 & -0.081 & -0.200 & -0.122 & -0.078 & -0.193 & -0.058 & -0.136 \\
\hline & $(0.150)$ & $(0.102)$ & $(0.101)$ & $(0.112)$ & $(0.094)$ & $(0.110)$ & $(0.180)$ & $(0.123)$ & $(0.087)$ \\
\hline$\%$ Impact (coef/mean) & $-1.47 \%$ & $-1.71 \%$ & $-1.23 \%$ & $-1.26 \%$ & $-1.50 \%$ & $-1.01 \%$ & $-1.32 \%$ & $-0.76 \%$ & $-1.93 \%$ \\
\hline REIS controls & $\mathrm{x}$ & $\mathrm{x}$ & $\mathrm{x}$ & $\mathrm{x}$ & $\mathrm{x}$ & $\mathrm{x}$ & $\mathrm{x}$ & $\mathrm{x}$ & $\mathrm{x}$ \\
\hline cty per cap real income & $\mathrm{x}$ & $\mathrm{x}$ & $\mathrm{x}$ & $\mathrm{x}$ & $\mathrm{x}$ & $\mathrm{x}$ & $\mathrm{x}$ & $\mathrm{x}$ & $\mathrm{x}$ \\
\hline yr x qtr fixed effects & $\mathrm{x}$ & $\mathrm{x}$ & $\mathrm{x}$ & $\mathrm{x}$ & $\mathrm{x}$ & $\mathrm{x}$ & $\mathrm{x}$ & $\mathrm{x}$ & $\mathrm{x}$ \\
\hline county fixed effects & $\mathrm{x}$ & $\mathrm{x}$ & $\mathrm{x}$ & $\mathrm{x}$ & $\mathrm{x}$ & $\mathrm{x}$ & $\mathrm{x}$ & $\mathrm{x}$ & $\mathrm{x}$ \\
\hline county $*$ linear time & $\mathrm{x}$ & $\mathrm{x}$ & $\mathrm{x}$ & $\mathrm{x}$ & $\mathrm{x}$ & $\mathrm{x}$ & $\mathrm{x}$ & $\mathrm{x}$ & $\mathrm{x}$ \\
\hline Observations & 81,753 & 81,753 & 81,753 & 161,955 & 161,955 & 161,955 & 115,682 & 115,682 & 115,682 \\
\hline R-squared & 0.24 & 0.17 & 0.19 & 0.51 & 0.41 & 0.34 & 0.41 & 0.34 & 0.28 \\
\hline mean of dependant variable & 13.35 & 6.81 & 6.53 & 15.83 & 8.13 & 7.70 & 14.60 & 7.57 & 7.03 \\
\hline
\end{tabular}

Notes: Each parameter is from a separate regression of the neonatal infant mortality rate (deaths in first 28 days per 1000 live births) on the Food Stamp implementation dummy. The treatment is assigned as of 3 months prior to birth (proxy for beginning of the $3^{\text {rd }}$ trimester). The estimation sample includes means by county-quarter for years including 1959-1977 where cells with less than 50 births are dropped. See data section for method for constructing number of births by county-quarter for 1959-1967. Estimates are weighted using the number of births in the cell and are clustered on county. Standard errors are in parentheses. Inflated impacts divide the parameter estimate by an estimate of the food stamp participation rate for the regression sample. 
Appendix Table 1: Percent of Observations with Non-Missing Data, by Year and Race

\begin{tabular}{|c|c|c|c|c|c|c|}
\hline \multicolumn{7}{|c|}{ A. WHITE } \\
\hline year & birthweight & parity & gestation & $\begin{array}{l}\text { mother's } \\
\text { education }\end{array}$ & legitimacy & $\begin{array}{c}\text { physician } \\
\text { attended birth }\end{array}$ \\
\hline 1968 & 1.00 & 1.00 & 0.83 & 0.00 & 0.71 & 1.00 \\
\hline 1969 & 1.00 & 0.99 & 0.60 & 0.62 & 0.66 & 1.00 \\
\hline 1970 & 0.99 & 0.99 & 0.60 & 0.66 & 0.66 & 1.00 \\
\hline 1971 & 1.00 & 0.99 & 0.60 & 0.66 & 0.67 & 1.00 \\
\hline 1972 & 1.00 & 0.98 & 0.60 & 0.66 & 0.67 & 1.00 \\
\hline 1973 & 1.00 & 0.96 & 0.61 & 0.69 & 0.67 & 1.00 \\
\hline 1974 & 1.00 & 0.99 & 0.61 & 0.70 & 0.67 & 1.00 \\
\hline 1975 & 1.00 & 0.99 & 0.61 & 0.70 & 0.67 & 1.00 \\
\hline 1976 & 1.00 & 0.99 & 0.64 & 0.76 & 0.67 & 1.00 \\
\hline 1977 & 1.00 & 0.99 & 0.65 & 0.76 & 0.60 & 1.00 \\
\hline \multicolumn{7}{|c|}{ B. BLACK } \\
\hline year & birthweight & parity & gestation & $\begin{array}{l}\text { mother's } \\
\text { education }\end{array}$ & legitimacy & $\begin{array}{c}\text { physician } \\
\text { attended birth }\end{array}$ \\
\hline 1968 & 1.00 & 1.00 & 0.82 & 0.00 & 0.75 & 1.00 \\
\hline 1969 & 0.99 & 0.99 & 0.52 & 0.59 & 0.70 & 1.00 \\
\hline 1970 & 0.99 & 0.99 & 0.54 & 0.65 & 0.70 & 1.00 \\
\hline 1971 & 1.00 & 0.98 & 0.54 & 0.65 & 0.71 & 1.00 \\
\hline 1972 & 1.00 & 0.95 & 0.53 & 0.66 & 0.72 & 1.00 \\
\hline 1973 & 1.00 & 0.92 & 0.57 & 0.74 & 0.72 & 1.00 \\
\hline 1974 & 1.00 & 0.98 & 0.57 & 0.76 & 0.71 & 1.00 \\
\hline 1975 & 1.00 & 0.98 & 0.57 & 0.76 & 0.71 & 1.00 \\
\hline 1976 & 1.00 & 0.98 & 0.60 & 0.82 & 0.71 & 1.00 \\
\hline 1977 & 1.00 & 0.98 & 0.60 & 0.83 & 0.64 & 1.00 \\
\hline
\end{tabular}

Notes: Authors' tabulations of 1968-1977 Natality detail files. 
Appendix Table 2: Causes of Death based on ICD-7 and ICD-8 codes

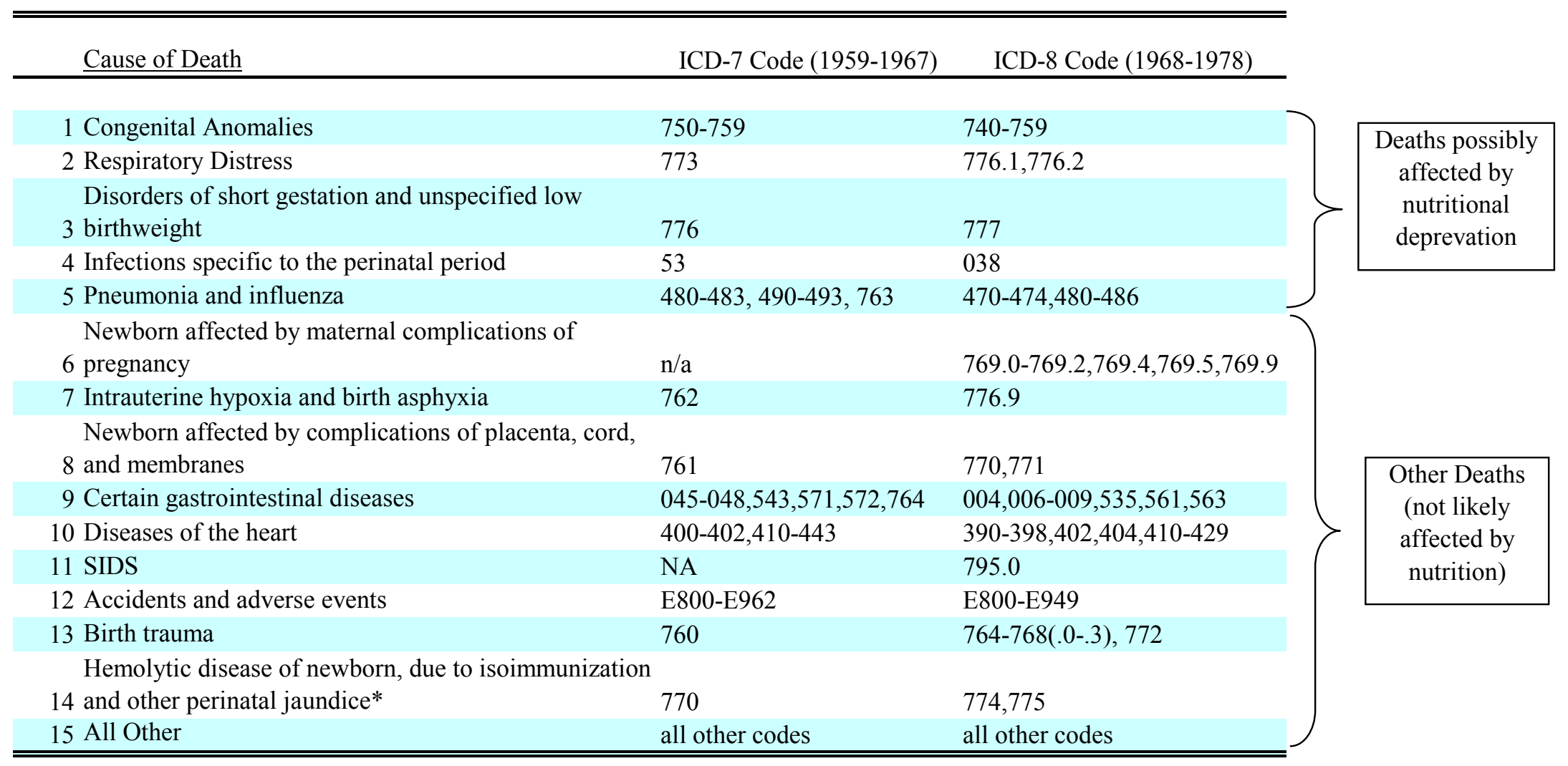


Appendix Table 3: Effect of FSP Implementation on Birth Outcomes using Expanded Sample 1959-1977, State-year data

\begin{tabular}{|c|c|c|c|c|c|c|}
\hline \multirow[b]{2}{*}{ Fraction of births less than: } & \multicolumn{2}{|c|}{ Original period $1968+$} & \multicolumn{2}{|c|}{ Full Period 1959+ } & \multicolumn{2}{|c|}{ Post-Pilot county period 1964+ } \\
\hline & $\begin{array}{c}<2,500 \mathrm{gms} \\
\text { (1) }\end{array}$ & $\begin{array}{c}<1,500 \text { gms } \\
\text { (2) }\end{array}$ & $\begin{array}{c}<2,500 \text { gms } \\
\text { (3) }\end{array}$ & $\begin{array}{c}<1,500 \text { gms } \\
\text { (4) }\end{array}$ & $\begin{array}{c}<2,500 \mathrm{gms} \\
\text { (5) }\end{array}$ & $\begin{array}{c}<1,500 \text { gms } \\
\text { (6) }\end{array}$ \\
\hline \multicolumn{7}{|l|}{ A. WHITES } \\
\hline FSP ( 1 qtr before birth quarter) & $\begin{array}{l}-0.0003 \\
(0.0007)\end{array}$ & $\begin{array}{l}-0.0002 \\
(0.0003)\end{array}$ & $\begin{array}{l}-0.0009 \\
(0.0005)\end{array}$ & $\begin{array}{c}0.0003 \\
(0.0002)\end{array}$ & $\begin{array}{l}-0.0003 \\
(0.0006)\end{array}$ & $\begin{array}{c}0.0003 \\
(0.0002)\end{array}$ \\
\hline Observations & 500 & 500 & 947 & 947 & 700 & 700 \\
\hline R-squared & 0.96 & 0.57 & 0.95 & 0.58 & 0.96 & 0.56 \\
\hline mean of dependant variable & 0.065 & 0.009 & 0.068 & 0.010 & 0.067 & 0.010 \\
\hline \% impact (coeff/mean) & $-0.441 \%$ & $-2.571 \%$ & $-1.280 \%$ & $2.795 \%$ & $-0.516 \%$ & $2.869 \%$ \\
\hline \multicolumn{7}{|l|}{ B. NONWHITES } \\
\hline FSP ( 1 qtr before birth quarter) & $\begin{array}{l}-0.0021 \\
(0.0019)\end{array}$ & $\begin{array}{l}-0.0002 \\
(0.0013)\end{array}$ & $\begin{array}{l}-0.0019 \\
(0.0016)\end{array}$ & $\begin{array}{l}-0.0003 \\
(0.0008)\end{array}$ & $\begin{array}{l}-0.0014 \\
(0.0018)\end{array}$ & $\begin{array}{l}-0.0002 \\
(0.0009)\end{array}$ \\
\hline Observations & 500 & 500 & 946 & 946 & 699 & 699 \\
\hline R-squared & 0.94 & 0.79 & 0.93 & 0.81 & 0.93 & 0.79 \\
\hline mean of dependant variable & 0.128 & 0.022 & 0.131 & 0.022 & 0.131 & 0.023 \\
\hline \% impact (coeff/mean) & $-1.621 \%$ & $-0.963 \%$ & $-1.486 \%$ & $-1.509 \%$ & $-1.093 \%$ & $-0.801 \%$ \\
\hline state \& year fixed effects & $\mathrm{x}$ & $\mathrm{x}$ & $\mathrm{x}$ & $\mathrm{x}$ & $\mathrm{x}$ & $\mathrm{x}$ \\
\hline REIS controls, per cap income & $\mathrm{x}$ & $\mathrm{x}$ & $\mathrm{x}$ & $\mathrm{x}$ & $\mathrm{x}$ & $\mathrm{x}$ \\
\hline state linear time trends & $\mathrm{x}$ & $\mathrm{x}$ & $\mathrm{x}$ & $\mathrm{x}$ & $\mathrm{x}$ & $\mathrm{x}$ \\
\hline
\end{tabular}

Note: Each parameter is from a separate regression of the outcome variable on the Food Stamp implementation dummy. The estimation sample includes the observations by race-state-year. In addition to the fixed effects, controls include, per capita state transfer income (public assistance, medical care, and retirement and disability benefits), and state real per capita income. The treatment is assigned as of one quarter before the birth and is a weighted average of the county FSP implementation using county births by month from 1968. Estimates are weighted using the number of births in the cell and are clustered on state. Standard errors are in parentheses. 
Appendix Figure 1: Percent of County Population on Food Stamps by Number of Years Since Program Start

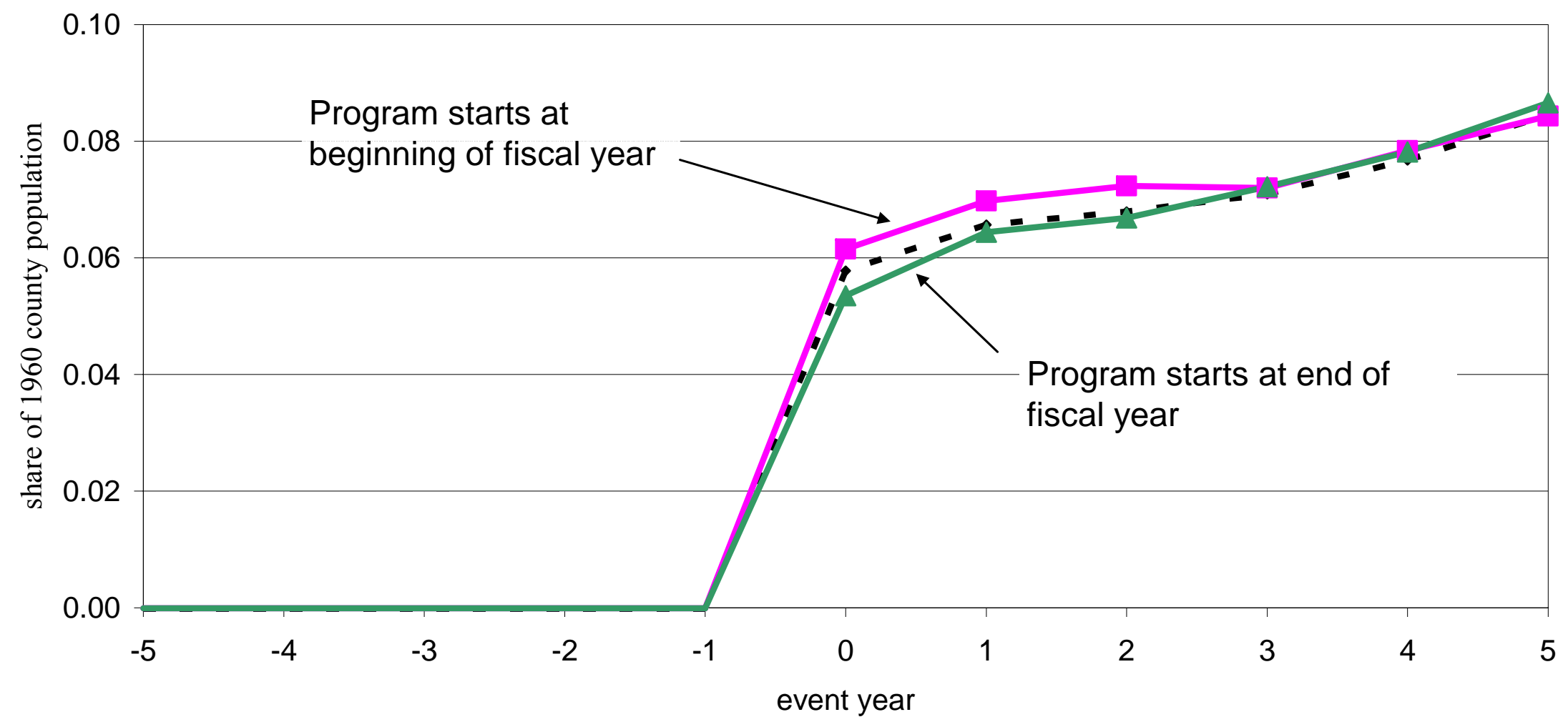

all counties program starts july, august, sept.

program starts april, may, june

Notes: Graph is an unweighted regression of county-year food stamp caseloads on a series of dummy variables tracking year relative to county FSP implementation year. County caseload is expressed as a share of the 1960 population. Source for caseload data is USDA (various years). 